\title{
APROXIMACIÓN SOCIAL A LA MESETA OCCIDENTAL PRERROMANA: RIQUEZA Y JERARQUIZACIÓN EN LA NECRÓPOLIS DE EL RASO (SECTOR EL ARENAL). CANDELEDA, ÁVILA
}

\author{
EdUARDO SÁNCHEZ MORENO * * \\ Departamento de Historia Antigua \\ Universidad Autónoma de Madrid
}

\section{Resumen}

Tomando como escenario el sector más conocido (El Arenal A) de los que componen la necrópolis de la Segunda Edad del Hierro de El Raso (Candeleda, Ávila), y tras una parte inicial de introducción al contexto arqueológico de la misma, se lleva a cabo por primera vez en esta necrópolis un análisis sobre riqueza y jerarquía aplicado a un conjunto de 64 sepulturas de cremación. A través del recuento de piezas de ajuar, del valor riqueza de las mismas y de otras pautas externas como la estructura de los enterramientos o su distribución espacial, se propone una lectura, todavia preliminar, de la distribución de riqueza material y del ordenamiento social de las gentes vetonas ahi enterradas.

\section{Summary}

The following pages try to make the first analysis on the richness and hierarchy of 64 cremation tombs belonging to the most well-known area (El Arenal A) of the Late Iron Age cemetery of El Raso (Candeleda, Ávila). After introducing the archaeological context of the place, an initial interpretation about wealth distribution and social structure is presented, according to the number of objects of the grave goods, their wealtb units and some other external aspects, the burial constructions (stone coverings) or their spatial position for example.

- Estamos en profunda deuda con el DR. F. Qtesada SANz sin cuyas orientaciones este trabajo nunca habría salido a la luz. Igualmente agradecemos al Dr. F. FERxÁNDEz GOMEz la lectura del texto original y los comentarios que gentilmente nos brindó. 


\section{INTRODUCCIÓN: LA NECRÓPOLIS DE EL RASO}

En uno de los piedemontes meridionales bajo las cumbres de la Sierra de Gredos, La Cabeza de la Laguna, se ubica uno de los yacimientos más destacados de la Segunda Edad del Hierro en la meseta, El Raso (Candeleda, Ávila). No sólo la envergadura de sus depósitos materiales sino también el hecho de ser uno de los pocos emplazamientos arqueológicos excavados en la provincia de Ávila en los últimos años, con metodología y planteamientos adecuados a nuestros días, hacen de este lugar un punto de referencia obligada para el estudio de la protohistoria meseteña. El yacimiento fue descubierto a principios de siglo por un pionero local, Fulgencio Serrano, que se puso en contacto con Juan Cabré y Antonio Molinero, siendo este último quien a finales de los años 50 da a conocer algunos resultados de sus trabajos esencialmente de prospección (FERNÁNDEZ Gómez et alii, 1990; MOLINERO, $1958 \mathrm{a} ; 1958 \mathrm{~b})$. Sin embargo, no fue hasta la década de los 70 cuando de la mano de Fernando Fernández Gómez se inician excavaciones sistemáticas en los tres ámbitos arqueológicos relacionables con El Raso: el poblado, la necrópolis y el santuario de Postoloboso (FERNÁNDEZ Gómez, 1973; 1986; 1993; FernÁNDEZ Gómez/López FernÁNDEZ, 1990; FERNÁNDEZ Gómez et alii, 1986-87). Desde entonces los trabajos arqueológicos han continuado hasta nuestros días, si bien de una manera discontinua, especialmente en los últimos años.

La necrópolis de El Raso se halla muy próxima al poblado amurallado, apenas 500 metros en dirección sur, en una planicie cercana a la orilla izquierda de la garganta de Alardos, límite provincial entre Cáceres y Ávila, y no muy alejada del pequeño municipio de El Raso' (figura 1). No está constituida por un conjunto único bien definido, sino por una serie de sectores más o menos independientes (seis principales: Las Guijas, El Arenal que se divide en tres núcleos, la Llaná, El Horco, El Campo de fútbol y la Huerta de Castañar), como se ve en otras necrópolis cercanas en lo geográfico y cultural (La Osera o Las Cogotas, por ejemplo). Cada núcleo presenta características definidas y en cada sector difiere la densidad de tumbas. El cementerio de El Raso ha sido objeto de expolio desde tiempo atrás, además de ser una zona muy alterada (labores agropecuarias, aperturas de caminos ...), con lo que tan sólo se han excavado cerca de 70 sepulturas, la mayoría del núcleo A del sector de El Arenal (figura 2) en dos únicas campañas de excavación (1970-71)². Pero todo parece indicar que se trataba de una inmensa necrópolis extendida desde el hábitat fortificado en dirección sur al valle del Tiétar hacia Madrigal de la Vera y hasta el pueblecito actual de El Raso (figura 1).

\footnotetext{
'Coordenadas: $40^{\circ} 11^{\prime} 05^{\prime \prime}$ latitud Norte - $1^{\circ} 40^{\prime} 05^{\prime \prime}$ longitud Oeste (Madrid). Hoja 577-III (27-46) (1:25.000) del Mapa Topográfico Nacional, Instituto Geográfico Nacional.

${ }^{2}$ En el verano de 1993 se llevó a cabo una campaña de urgencia en la zona de Las Guijas (Núcleo B), una vez más ante la acción de furtivos. La extensión de la nueva área excavada es de $300 \mathrm{~m}^{2}$ y se exhumaron un total de 53 sepulturas (desde la $n^{2} 67$ a la $n^{2} 120$ ). Desde aquí nuestra gratitud hacia el Dr. FERNÁNDEz Gómez, director de los trabajos. por el envío y el permiso de uso de los datos de la memoria inédita de la excavación, entregada a la Consejería de Cultura de la Junta de Castilla y León. No obstante, la utilización de esa información en estas páginas es sólo referencial como punto comparativo en algún momento, habida cuenta que el análisis que llevamos a cabo se limita al sector de El Arenal.
} 


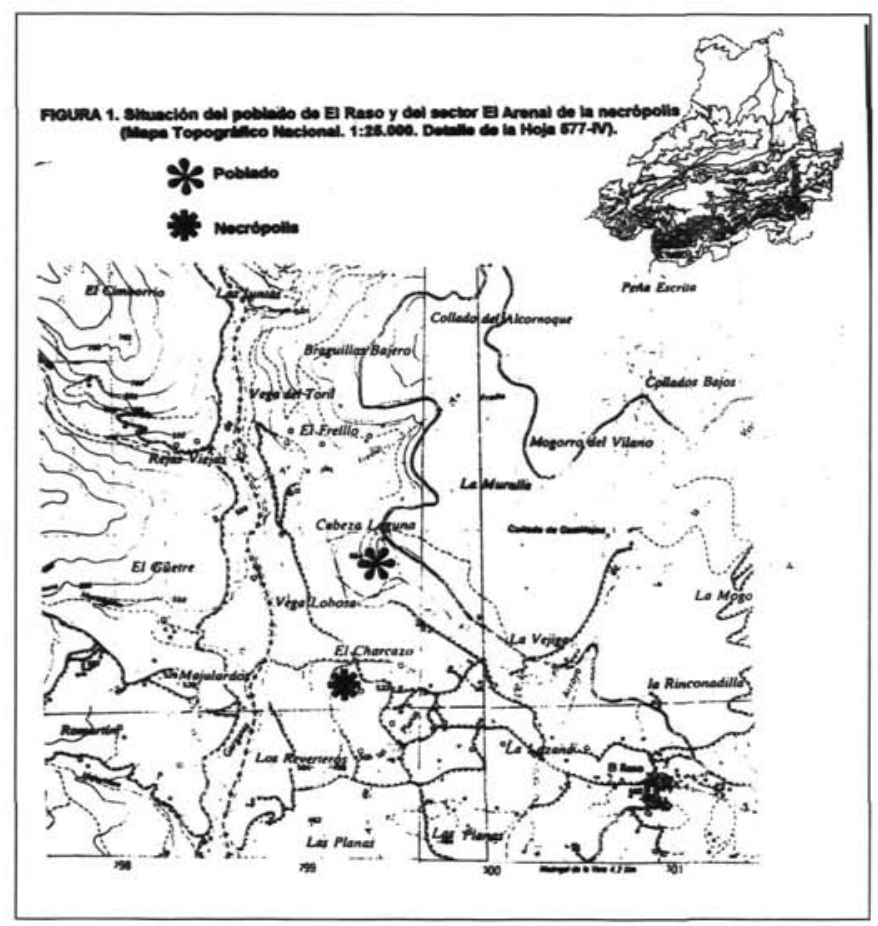

Figura 1. Situación del poblado de El Raso y del sector El Arenal de la necrópolis (Mapa Topográfico Nacional. 1:25,000. Detalle de la Hoja 577-IV)

Por la cronología de los ajuares, a la que más tarde nos referiremos, Fernández Gómez deduce que la necrópolis (en realidad los núcleos por él excavados, un muestreo minoritario en relación al total del cementerio) no es coetánea al poblado amurallado, sino anterior en el tiempo en algo más de un siglo. Efectivamente, el castro, un auténtico oppidum en territorio de los vetones (Almagro Gorbea, 1994, 41, 63; SÁnchez Moreno, 1995, 14-15) como últimamente prefiere denominarse a este tipo de asentamientos, es datado a finales del siglo III a.C. y presenta una ocupación hasta mediados del siglo I a.C., en que es abandonado pacíficamente. La necrópolis grosso modo abarca un marco cronológico entre el siglo $\mathrm{V}$ a.C. y el siglo III a.C., y es puesta en relación por Fernández Gómez con un hábitat anterior, sin defensas y conocido sólo por prospección, localizado en una zona baja muy próxima a la necrópolis denominada El Castañar ${ }^{3}$. El planteamiento parece lógico, pero en lugar de pensar en dos necrópolis diferentes, como hace Fernández Gómez (la excavada perteneciente al pobla-

${ }^{3}$ El traslado desde el poblado en llano y abierto -éste sí que parece sufrir una destrucción- al castro situado más arriba viene determinado, según Fernández Gómez, por el clima de inseguridad existente ante los enfrentamientos iniciales entre romanos y cartagineses y la posterior incursión de los primeros hacia el interior de la meseta (FER Á dDez Gómez, 1986, 529, nota n² 436; 1993, 153-156). 


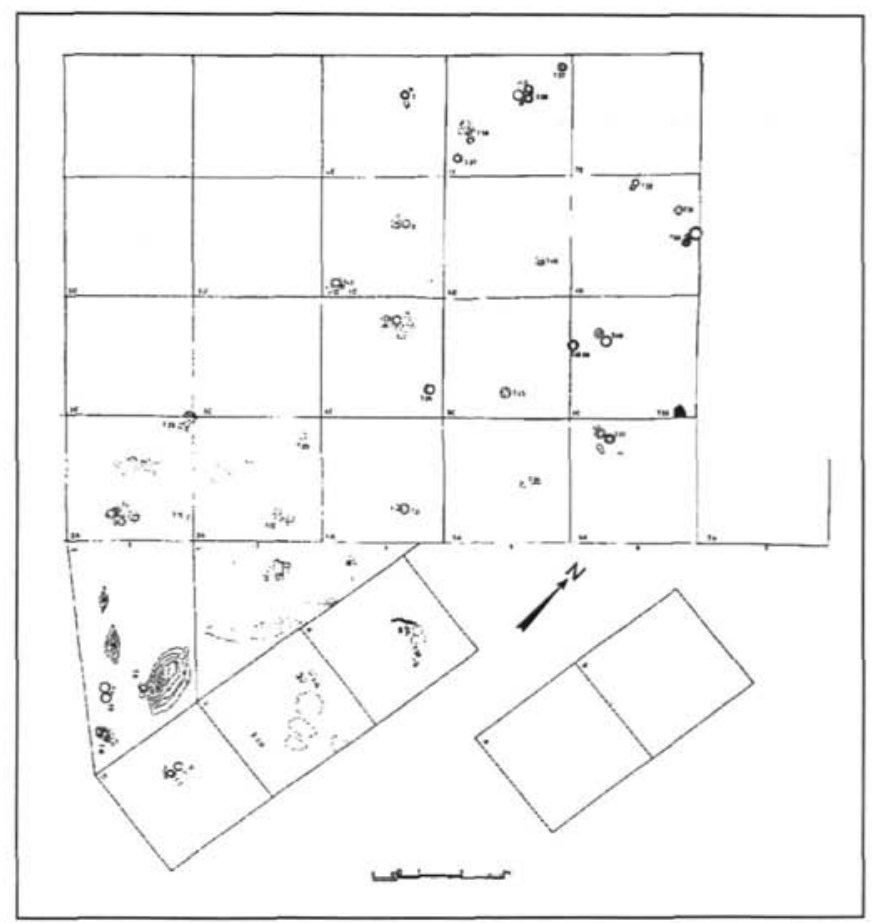

Figura 2. Plano del núcleo A, sector El Arenal, de la necrópolis de El Raso. (FERNÁNDEZ GÓMEZ, 1996: fig. 293bis, 548-549)

do de El Castañar, y una segunda, todavía sin localizar, vinculada al oppidum amurallado), sugerimos la posibilidad de estar ante un único y extenso conjunto cementerial en el espacio -a las áreas excavadas habría que añadir todos los demás sectores sin exhumar que se extienden por varias hectáreas-y en el tiempo, -acaso desde fines del siglo VI a.C.-, por algunas piezas importadas halladas en el entorno (FERNÁNDEZ GómEZ, 1972; 1991; 1996), hasta los siglos finales del Ier milenio a.C. Este patrón de ocupación, sucesión de dos poblados -abierto el primero, y fortificado el más tardío- y una amplia necrópolis unitaria, parece que se impone en puntos tan próximos a El Raso como la necrópolis de Pajares, en Villanueva de la Vera, Cáceres (González Cordero et alii, 1991; Celestino et alii, e.p.), con un hábitat del Primer Hierro en las inmediaciones y un castro amurallado (Cerro Castrejón) algo posterior y más alejado del cementerio, tal y como hemos sugerido en otro lugar (SÁNCHEZ MORENO, 1995, 29, 41-42). De forma paralela podemos interpretar la dinámica de comportamiento de El Raso y la conexión entre poblados y necrópolis, aunque sólo los resultados de nuevas excavaciones darán validez definitiva, o no, a la hipótesis que aquí lanzamos. 


\section{EL SECTOR DE EL ARENAL}

En el estudio que desarrollamos sólo contemplamos las 64 sepulturas del sector El Arenal, ubicado en terrenos comunales, junto al campo de fútbol y a una vivienda a la derecha de la colá o camino que desde el municipio de El Raso se dirige al de Madrigal de la Vera (Fernández Gómez, 1986, 530). Se distinguen dentro de este sector tres núcleos diferentes: A, B y C, con 52,9 y 3 sepulturas respectivamenté ${ }^{4}$. El terreno está bastante arrasado y todavía afloran fragmentos de cerámica en superficie, restos de las lajas que cubrían las tumbas y hoyos debidos a manos clandestinas. La estratigrafía revela tres claros niveles. El primero, estéril de tierra vegetal, con una potencia que oscila entre 18 y $42 \mathrm{~cm}$. El segundo, ya arqueológico, de tierra blanquecino-amarillenta muy polvorienta que esconde la mayoría de las sepulturas, nunca a más de $50 \mathrm{~cm}$., con una profundidad entre 10 y $45 \mathrm{~cm}$. El tercer estrato discontinuo aparece únicamente en el núcleo A y tan solo en algunos lugares; parece estar en relación con corrientes de agua subterráneas y está formado por tierra arenosa, parda y húmeda, que contrasta con el nivel superior, polvoriento y seco. Finalmente se halla el nivel natural, de roca granítica más o menos descompuesta.

Dentro de un comentario general que contextualice los hallazgos de El Arenal en relación a su entorno geográfico-cultural y que sirva de preámbulo al análisis social que presentamos más adelante, podemos destacar que la tipología de las tumbas de El Arenal sigue el patrón funerario clásico del círculo cultural de Cogotas II: exclusividad del rito cremador, urnas depositadas sobre un hoyo poco profundo, apoyadas en piedras o fragmentos cerámicos para mantener la estabilidad y protegidas con tapaderas, platos o incluso alguna piedra plana. A los vasos cinerarios acompañan el resto de elementos del ajuar, y todo el conjunto queda cubierto por un amontonamiento de tierra o por un cuerpo de grandes lajas de granito que no llegan a aparecer en superficie, pero sin ninguna manifestación exterior, ni estructura tumular ni estela hincada, como en cambio sí ocurre en otras necrópolis vetonas, casos de La Osera y Las Cogotas, en Ávila (CABRÉ, 1932; CABrÉ et alii, 1950), o El Mercadillo en Botija, Cáceres (Hernández, 1991; Hernández/Rodríguez, 1990; Hernández/Galán, 1996, 1820. 83-84). Los ajuares, bastante frecuentes en las sepulturas excavadas, muestran variadas piezas: además de las urnas cinerarias y otras formas cerámicas (vasos, copas, escudillas, cuencos, jarros, vasos en miniatura) - que aparecen tanto a mano como a torno-, objetos de bronce (fíbulas, restos de recipientes, brazaletes, pinzas, cuentas de collar, botones..., e inclu-

+ No existe una representación cartográfica conjunta de los sectores de la necrópolis en la memoria de excavación. ejemplar por otra parte (FER NáNDEz GÓmez, 1986, 529-877). Se incluyen planos parciales de los tres subsectores de El Arenal, pero los de los núcleos B y C aparecen descolocados en el tomo primero dedicado al poblado (Frrvández Gomez, 1986. 394-395, fig. 402 y 417, fig. 422). Ello dificulta la visión global de las sepulturas y la relación espacial de los tres núcleos, de los que sencillamente se dice que el B se halla a $30 \mathrm{~m}$. al oeste de la cuadrícula del núcleo $\mathrm{A}$, en una pequeña elevación apenas perceptible, y que el $\mathrm{C}$ se sitúa al norte de la misma cuadrícula (sin especificar la distancia), junto a una vivienda, entre el camino o colá a Madrigal de la Vera y la trocha o vereda que desde el camino anterior lleva a El Raso (FERXìidez Gomfz, 1986, 534). El conocimiento geográfico es insuficiente para llevar a cabo un trabajo de distribución espacial de la necrópolis. De todas maneras, de entrada no parece vislumbrarse una organización muy determinada del espacio funerario (excavado) por áreas concretas o círculos jerírquicos en El Arenal, a excepción de las tres tumbas con armas del núcleo $\mathrm{C}$ y de cierta tendencia de alguna de las sepulturas más ricas en ajuar por agruparse en la zona suroeste del núcleo A (figura 2). 
so bocados de caballo, si bien fuera de contexto), objetos de hierro (espadas, puñales, falcata, soliferrea plegados, puntas de lanza y regatones, restos de escudo, cuchillos afalcatados, navajas, pinzas...), ciertos objetos exóticos (ungüentario de vidrio polícromo, cuentas de collar de vidrio oculadas, copas de barniz negro, cerámica de engobe rojo de reminiscencia meridional...) y otros elementos varios (fusayolas, bolas cerámicas, afiladoras y piedras rodadas...).

En cuanto a la estructura de las sepulturas, la variedad es muy escasa. Únicamente cabe diferenciar, como ya se ha señalado, la presencia de una cobertura de lajas de granito sin trabajar, en número variable (desde dos a cerca de veinte en algunos casos) y de longitud pocas veces superior al medio metro 5 . Tal como nos indica la figura 3, el porcentaje de sepulturas con cobertura (46\%) frente al de las que no la presentan ( $48 \%)$ es muy parejo, manifestándose este dato apriorísticamente de poco peso como índice de diferenciación social. Resulta por tanto obligado hacer un examen contrastado de los ajuares de las sepulturas para intentar avanzar algo más en la caracterización social de las gentes enterradas en El Raso.

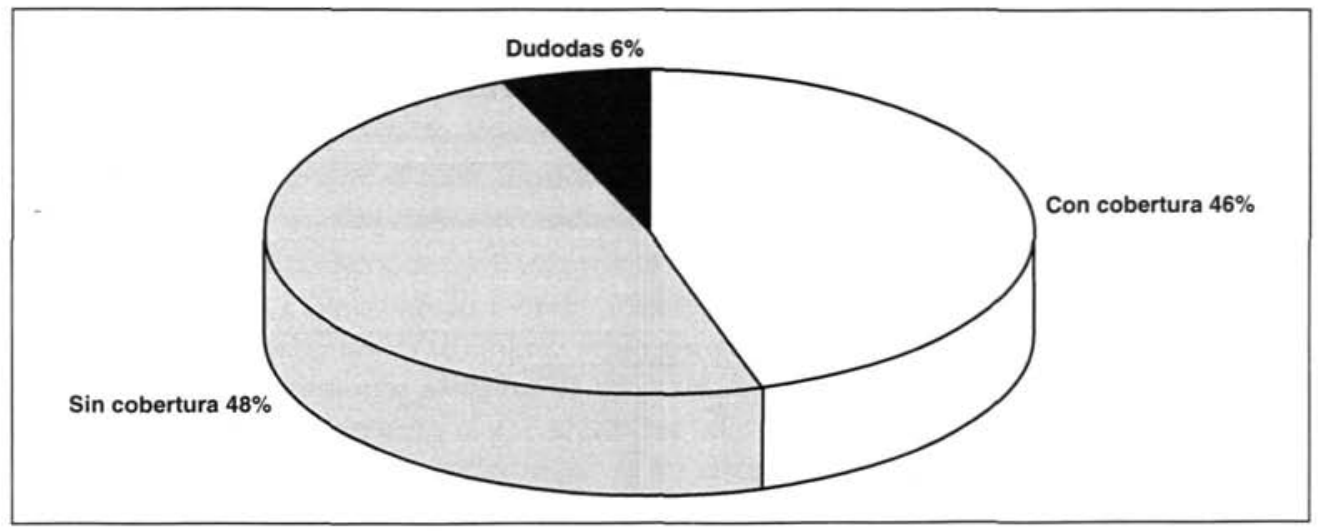

Figura 3. Porcentaje de sepulturas con cobertura sobre el total.

${ }^{5}$ Una interesante novedad encontramos en la zona B de Las Guijas. Las excavaciones de urgencia llevadas a cabo en Septiembre de 1993 depararon el hallazgo de seis túmulos (A-F), a modo de estructuras de cubrición más o menos complejas, inéditos hasta el momento en El Raso. En el interior de cada uno de ellos se hallaba un número variado de tumbas (desde las dos del túmulo $\mathrm{A}$ o una única en los túmulos $\mathrm{E}$ y $\mathrm{F}$, hasta las nueve del túmulo C). Además de las 28 sepulturas bajo los túmulos, que recuerdan en algo a los conocidos de La Osera, alrededor de los mismos se distribuian otros enterramientos ( 23 en total) que aparecian mayoritariamente con el mismo tipo de cubrición, a base de lajas de granito, registrado en el sector de El Arenal. Tal disposición de enterramientos queda lejos de estar perfectamente definida, toda vez que la intervención arqueológica tuvo más de tanteo aleatorio, siguiendo los destrozos de los furtivos, que de análisis pormenorizado sobre un sector. 
La gran mayoría de enterramientos contienen una única cremación (figura 4). Tan sólo un $5 \%$ presentan dos cremaciones ${ }^{6}$ y el $15 \%$ no registran restos humanos aunque sí tienen vasos de ofrendas (tabla I). La presencia de ajuar es mayoritaria. A excepción de la n² 35 que no tiene ni ajuar ni urna (las cenizas descansan sobre el fondo del hoyo), el resto de sepulturas presentan al menos un elemento material. El 18,75\% de las tumbas muestran sólo la urna cineraria sin más ${ }^{7}$, correspondiendo al más del $80 \%$ restante contar con piezas específicas del ajuar, cuya valoración a efectos de estimación social será atendida más adelante (tabla II).

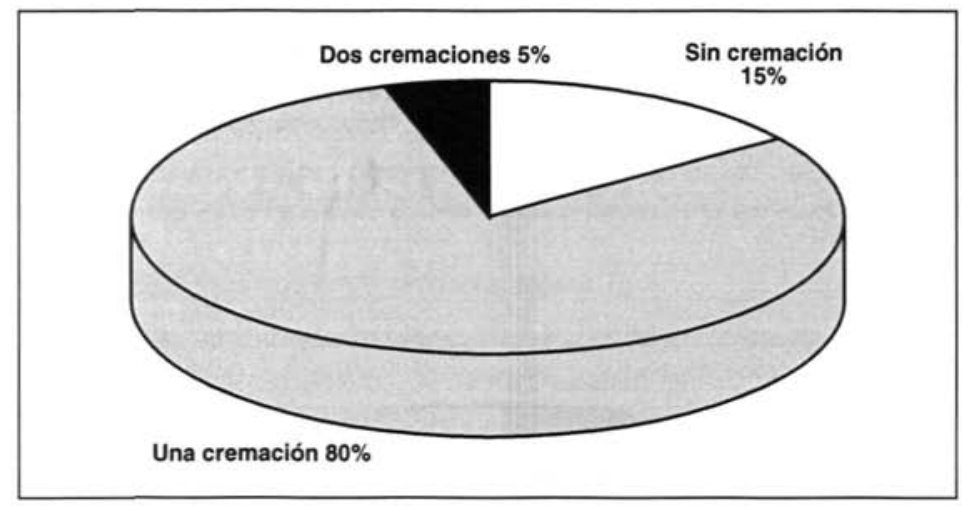

Figura 4. Porcentaje de número de cremaciones en las sepulturas.

El elemento más abundante es la cerámica, tanto a mano como a torno. Sólo cuatro sepulturas $(17,35,52$ y 53) no tienen ninguna pieza cerámica. La variedad de vasos cerámicos de ofrenda es amplia, oscilando desde las once piezas de la sepultura 42, otra de las más importantes, las siete de la sepultura 4 o las seis de la 5, a la presencia de un único vaso, al margen de la urna funeraria, que se registra en el mayor número de casos. De forma parecida la proporción en el número de piezas tipo urna (además de la que contiene la cremación) en las sepulturas es diversa (figura 5). Casi el $40 \%$ tienen una sola, un $30 \%$ presentan dos, el $15 \%$ tres, un $12,5 \%$ no contabilizan urna, y más minoritariamente se enumeran casos con cuatro, cinco o seis urnas (1,5\% en las tres últimas variantes).

Probablemente el dato más significativo en cuanto a la categoría de un enterramiento ha sido, y lo sigue siendo, la presencia de armamento. La constatación de algún tipo de arma

${ }^{6}$ Sepulturas números 20,36 y 42. Especialmente la n² 20, una de las más ricas de la necrópolis, parece corresponder a una pareja: una urna contenia un ajuar guerrero (soliferreum, espada de antenas atrofiadas, vaina, punta de lanza, cuchillo afalcatado...), mientras que la otra incluía elementos tradicionalmente tenidos por femeninos, como un adorno de bronce y una fusayola (FERXÁNDEZ GOMEZ, 1986, 766, 590-595). En la zona recientemente excavada de Las Guijas B, la sepultura 109 presentaba tres urnas cinerarias con cremaciones, dos eran mujeres adultas y la tercera una persona joven de sexo indeterminado.

- Sepulturas número 18, 23, 25, 33, 35, 40 bis, 46, 47, 51, 54, 60 y 61. Además, consideramos significativo el hecho de que cinco de ellas (41\%) son enterramientos alterados o parcialmente robados. En Las Guijas B la cifra de sepulturas con sólo la urna contenedora es del $8 \%$. 


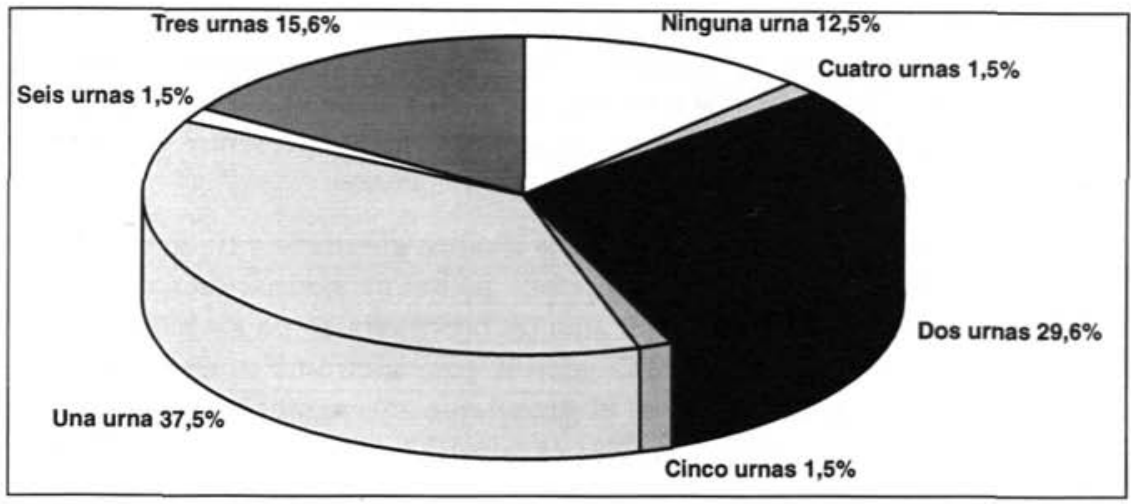

Figura 5. Proporción de número de urnas en las sepulturas

en una sepultura ha supuesto tradicionalmente la caracterización de una función social (la del guerrero) y, muy frecuentemente, la asociación a la misma de las ideas de riqueza y poder (estatus social). No obstante, como más adelante se verá, no resulta tan fácil la confirmación práctica de tales asunciones, ni tan clara la derivación de un nivel social concreto a partir de una deposición determinada de objetos materiales. En El Arenal observamos que doce sepulturas, esto es el 19\% sobre el total, introducen armas (figura 6) ${ }^{8}$. Lógicamente la envergadura del ajuar guerrero no es la misma en todos los casos. En la mitad de los enterramientos con armas se da un único elemento, sea una punta de lanza (sepulturas 34, 43 y 52), una abraza-

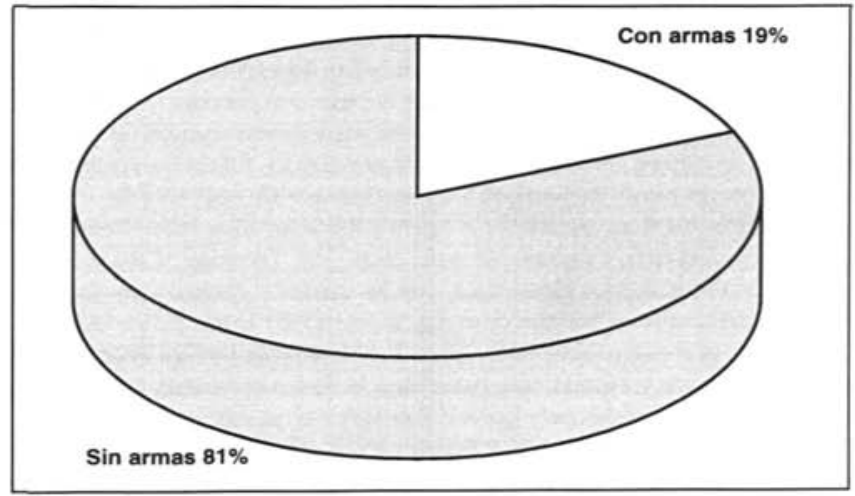

Figura 6. Proporción de sepulturas con armas

${ }^{8}$ Por sub-sectores la distribución de sepulturas con armas es la siguiente: el núcleo A contabiliza ocho y proporcionalmente el 15,3\% (números 13, 20, 30, 34, 36, 43, 52 y 59); una única tumba (número 26) en el núcleo B, $11,1 \%$; mientras que en el núcleo $\mathrm{C}$ las tres únicas sepulturas (números 63, 64 y 66) presentan armas y suben el porcentaje al pleno $100 \%$. Por otra parte, una proporción similar de tumbas de guerrero se da en el núcleo $\mathrm{B}$ de Las Guijas, donde cinco sobre treinta y cuatro sepulturas intactas (15\%) tienen armas. 
dera de escudo (sepultura 59), un soliferreum (sepultura 25) o un dudoso fragmento de regatón (sepultura 36). Son seis los enterramientos que comprenden una panoplia guerrera completa (sepulturas 13, 20, 30, 63, 64 y 66), en la que espada con su vaina, soliferreum, escudo, lanza, cuchillo afalcatado y pinzas de hierro están prácticamente presentes y constituyen los componentes tipo del guerrero de El Raso (tabla II) ${ }^{9}$.

Este escalonamiento en la categoría de los ajuares, guerreros y no guerreros, supone la base instrumental desde la que se han propuesto pautas de agrupación social, jerarquía y riqueza. Consideramos oportuno introducir aquí un breve esbozo de los modelos aplicados sobre otras necrópolis vetonas del círculo Cogotas II, para contrastar su resultado con el que nosotros obtenemos en nuestro análisis de El Arenal que afrontamos en el siguiente apartado. Todas las necrópolis vetonas mínimamente excavadas señalan la existencia de ajuares de desigual categoría (SÁnchez Moreno, 1995, 68-77 y 333-337). Sobre este dato se han llevado a cabo análisis sociales, que interpretan distintos rangos a partir de su proporción en cálculos estadísticos. Martín Valls (1985, 121-123; 1986-87, 75-76), en el estudio que realiza en las necrópolis de La Trasguija, en Las Cogotas -la que ofrece datos más fiables por estar excavada y publicada en su totalidad- y La Osera, distingue cuatro tipos diferentes de ajuar según su calidad ${ }^{10}$ frente al $85 \%$ de tumbas sin ajuar en Las Cogotas y a un $52 \%$ en la zona VI de La Osera (la única publicada) ${ }^{11}$. De estos datos deduce la existencia de una sociedad conformada en cuatro niveles sociales: 1) a la cabeza una minoría aristocrática y guerrera, en relación

'En otras necrópolis vetonas la panoplia de guerrero más habitual viene representada por la espada o puñal, dos puntas de lanza y un escudo en Las Cogotas (KLRTZ, 1986-87, 457; 1987, 23, 279); la espada o puñal, una o varias lanzas, un escudo y un cuchillo en La Osera (CABRÉ et alii, 1950); y la espada o puñal y dos puntas de lanza en El Romazal. Villasviejas de Tamuja, Botija (HerNáxDEZ, 1991, 262). Lo cual se adecua en lineas generales con las noticias que las fuentes ofrecen del armamento de los pueblos lusitanos (Estrabón, III, 3, 6: "Dicen que los lusitanos son diestros en emboscadas y persecuciones, ágiles, listos y disimulados. Su escudo es pequeño, de dos pies de diámetro. y cóncavo por su lado anterior; lo llevan suspendido por delante con correas, y no tiene, al parecer, abrazaderas ni asas. Van armados también de puñal o cuchillo; la mayor parte llevan corazas de lino, y pocos cota de malla y cascos de tres cimeras. Otros se cubren con cascos tejidos de nervios; los infantes usan grebas y llevan varias jabalinas: algunos sirvense de lanza con punta de bronce"; traduc. GARcí Y BEuDO, 9ª edic. 1986, 118. Estrabón, III, 4. 15: "luchando al modo de bandoleros, iban armados a la ligera y llevaban sólo, como hemos dicho de los lusitanos, jabalina, honda y espada"; traduc. Garcia Y BeudDo, $9^{2}$ edic. 1986, 152. Diodoro, V, 34, 4-5: "(los lusitanos) Para la guerra llevan escudos muy pequeños, tejidos de nervios, con los cuales y gracias a su dureza pueden defender su cuerpo holgadamente. En su lucha lo manejan con destreza, moviéndolo a uno y otro lado del cuerpo y rechazando con habilidad todos los tiros que caen sobre ellos. Usan también picas hechas enteramente de hierro y con la punta a modo de arpón y llevan casco y espada muy parecida a la de los celtíberos. Lanzan sus picas con precisión y a larga distancia y causan a menudo heridas muy graves. Son ágiles en sus movimientos y ligeros en la carrera, por ello huyen o persiguen con rapidez"; traduc. GaRCia Y BeudDO, 1977, 45-46).

${ }_{10}$ Tipo I: ajuares de guerrero, en los que destaca, además de otros objetos, la aparición de armas; con 4 subcattegorias: a) ajuares suntuarios, con armas de gran calidad y profusamente decoradas, b) con arreos de caballo, c) ajuares completos pero con armas más sencillas, y d) con tan solo 1 ó 2 elementos; Típo II: ajuares de artesanos, en Ios que aparecen útiles como punzones u hoces; Tipo III: ajuares femeninos, con elementos como fusayolas, y más raramente alguna fibula, sortija o collar; Tipo IV: ajuares excepcionales, con un simple objeto (fragmento de hierro, alguna miniatura...).

$"$ Recordemos que en El Arenal sólo el 18,75\% de las sepulturas no tienen ajuar, y de ellas el $41 \%$ han sido parcialmente violadas. No obstante, la diferencia en número es notable: en El Arenal estamos trabajando con 64 sepulturas, mientras que en la zona VI de La Osera la cantidad es de 517 y en Las Cogotas el número asciende a cerca de 1.600 enterramientos. 


\begin{tabular}{|c|c|c|c|c|c|c|}
\hline \multicolumn{7}{|c|}{$\begin{array}{l}\text { Tabla } 1 . \\
\text { EL ARENAL (EL RASO, CANDELEDA). CARACTERIZACIÓN DE LAS SEPULTURAS }\end{array}$} \\
\hline SEPULTURA & NUCIEO & $\begin{array}{l}\text { ROBADA / } \\
\text { ALTERADA }\end{array}$ & $\begin{array}{l}\text { COBERTURA } \\
\text { DE PIEDRA }\end{array}$ & $\begin{array}{l}\text { CREMACIÓN } \\
\text { NUMERO DE } \\
\text { INDIVIDUOS }\end{array}$ & URNA CERÁMICA & $\begin{array}{l}\text { VASOS CERÁMICOS } \\
\text { OFRENDA }\end{array}$ \\
\hline 4 & $\mathrm{~A}$ & so & St & 1 & 3 & 7 \\
\hline 5 & $A$ & so & St & 1 & 2 & 6 \\
\hline 6 & $\mathrm{~A}$ & so & so & 1 & 2 & 1 \\
\hline 7 & $A$ & so & SI & 1 & 2 & 4 \\
\hline 8 & $A$ & so & so & $i$ & 2 & 3 \\
\hline 9 & $A$ & so & $\mathrm{sl}$ & 1 & 3 & $\frac{3}{0}$ \\
\hline 10 & $\mathrm{~A}$ & SI & so & 1 & 2 & 0 \\
\hline 11 & B & so & $\mathrm{Sl}$ & 1 & 5 & 5 \\
\hline 12 & $\mathrm{~A}$ & so & SI & 1 & 6 & 3 \\
\hline 13 & $A$ & xo & so & 0 & 0 & 1 \\
\hline 14 & B & so & so & 0 & 0 & 4 \\
\hline 15 & $A$ & St & so & 1 & 2 & 0 \\
\hline 16 & $A$ & so & so & $i$ & 2 & 2 \\
\hline 17 & $A$ & $\mathrm{sl}$ & so & 1 & 0 & 0 \\
\hline 18 & $A$ & SI & so & 1 & 1 & 0 \\
\hline 19 & B & so & so & 0 & 0 & 3 \\
\hline 20 & $\mathrm{~A}$ & so & $\mathrm{Sl}$ & 2 & 2 & 5 \\
\hline 21 & $A$ & so & No & 1 & 2 & 1 \\
\hline 22 & $A$ & so & so & 1 & 3 & 5 \\
\hline 23 & B & so & $?$ & 1 & 1 & 0 \\
\hline 24 & $A$ & so & St & 1 & 2 & 5 \\
\hline 25 & $A$ & SI & $?$ & 1 & $i$ & 0 \\
\hline 26 & B & so & St & 0 & 1 & 2 \\
\hline 27 & $A$ & so & si & 0 & 1 & 1 \\
\hline 28 & $A$ & so & so & 0 & 2 & 2 \\
\hline 29 & $A$ & so & $\mathrm{sl}$ & 1 & 3 & 5 \\
\hline 30 & $A$ & so & st & 1 & 3 & 2 \\
\hline 31 & B & so & St & 1 & 2 & + \\
\hline 32 & $A$ & Sl & $?$ & 1 & 1 & 0 \\
\hline 33 & $\mathrm{~A}$ & so & St & 1 & 1 & 0 \\
\hline 34 & $A$ & Sl & $?$ & 1 & 1 & 0 \\
\hline 35 & $A$ & so & St & 1 & 0 & 0 \\
\hline 36 & $\mathrm{~A}$ & so & st & 2 & 4 & 4 \\
\hline 57 & $A$ & xo & Si & 1 & 3 & 5 \\
\hline 38 & $A$ & so & so & 1 & 1 & 5 \\
\hline 39 & $\mathbf{A}$ & so & xo & 1 & 1 & 0 \\
\hline 40 & B & xo & $\mathrm{SI}$ & 0 & 2 & 1 \\
\hline 40 bis & $B$ & So & so & 0 & 0 & 1 \\
\hline 41 & $\mathrm{~A}$ & $\mathrm{Sl}$ & $\mathrm{St}$ & 1 & 1 & 3 \\
\hline 42 & $A$ & so & St & 2 & 3 & 11 \\
\hline 43 & $A$ & so & S1 & 1 & 1 & 4 \\
\hline 44 & $A$ & xo & $\mathrm{SI}$ & 1 & 2 & 0 \\
\hline 45 & $\mathrm{~A}$ & so & so & 1 & 1 & 0 \\
\hline 46 & $B$ & xo & so & 1 & 1 & 0 \\
\hline $4^{7}$ & $A$ & so & No & 1 & 1 & 0 \\
\hline 48 & $\mathrm{~A}$ & xo & so & 1 & 1 & 0 \\
\hline 49 & $A$ & xo & $\mathrm{Sl}$ & 1 & 1 & 1 \\
\hline 49 bis & $\mathrm{A}$ & No & S1 & 1 & 2 & 0 \\
\hline 50 & $A$ & No & so & 1 & 2 & 2 \\
\hline 51 & $\mathrm{~A}$ & so & so & 1 & 1 & 0 \\
\hline 52 & $A$ & so & so & 1 & 0 & 0 \\
\hline 53 & $A$ & so & so & 1 & 0 & 0 \\
\hline 54 & $\mathrm{~A}$ & No & so & 1 & 1 & 0 \\
\hline 55 & $\mathrm{~A}$ & $\mathrm{SI}$ & xo & 1 & 1 & 1 \\
\hline 56 & $A$ & so & SI & 1 & 1 & 4 \\
\hline 57 & $\mathrm{~A}$ & SP & No & 1 & 1 & 1 \\
\hline 58 & $A$ & so & St & 1 & 3 & 5 \\
\hline 5) & $\mathrm{A}$ & so & so & 1 & 2 & 3 \\
\hline 60 & $\mathrm{~A}$ & so & so & 1 & 1 & 0 \\
\hline 61 & $\mathrm{~A}$ & si & so & 1 & 1 & 0 \\
\hline 62 & $\mathrm{~A}$ & so & so & 0 & 3 & 3 \\
\hline 63 & C & so & SI & 1 & 3 & 2 \\
\hline 64 & C & so & St & 0 & 2 & 3 \\
\hline 66 & C & xo & SI & 1 & 2 & 5 \\
\hline
\end{tabular}


a la cual hay que situar unos pocos enterramientos femeninos con bienes de lujo; 2) tras ésta, un grupo más numeroso de guerreros con una panoplia más reducida, asociados a tumbas femeninas bastante más sencillas en las que predomina el hallazgo de fusayolas; 3) un grupo intermedio de artesanos y comerciantes no excesivamente representado (en nuestra opinión la identificación de este grupo se apoya en argumentos muy débiles); y por último, en la base social, 4) la extensa presencia de una masa social humilde sin ajuar, sobre la cual la arqueología no puede precisar con suficiente criterio su catalogación como esclavos (Ruiz ZAPATERO/ChAPA, 1990, 368).

A conclusiones similares a las de Martín Valls llegan otros autores. GonZález-TABLAS (1985, 47), en su estudio social de la necrópolis de Las Cogotas, singulariza (con la particularidad de añadir su interpretación sobre la correspondiente actividad realizada por cada escalón social) un primer grupo dirigente, subdividido en distintas categorías, que ostentaría el poder político, militar y religioso. Tras él, un nivel intermedio de artesanos en general (alfareros, herreros, fundidores, canteros, tejedores...) y por último la base mayoritaria de gente llana sin apenas bienes, destinada a trabajos primarios agrícolas y ganaderos, empleada en las tareas de construcción de obras y en su mantenimiento, y que constituiría la base del ejército de la comunidad en cualquier conflicto bélico. Aplicando modelos de la antropología evolucionista anglosajona, CASTRO MARTÍNEZ (1986) prefiere hablar, también para Las Cogotas, de cinco rangos sociales: 1 ) el evidente conjunto de dirigentes, reflejado en tumbas con elementos de prestigio y autoridad (armas decoradas, arreos de caballo...); 2) un grupo variado de guerreros, artesanos y especialistas metalúrgicos, a los que corresponden tumbas con armas menos lujosas; 3) la agrupación de mujeres e hijos de los personajes más poderosos, con ajuares especiales en los que encontramos adornos de metal, pasta vítrea, hueso...; 4) un nivel de población media, con sencillos ajuares cerámicos, y 5) la mayoría de la población (más del $75 \%$ en Las Cogotas), sin elementos de ajuar ni urnas especiales, claramente diferenciados del resto de categorías sociales. Debemos citar también el trabajo de KuRTz (1987). Con base en la revisión de los ajuares de la necrópolis de La Trasguija, este autor insiste igualmente en la idea de una élite minoritaria identificada con símbolos de poder (armamento) y con los ajuares más fecundos a la cabeza de la sociedad de Las Cogotas, conformada internamente en órganos suprafamiliares; pero no ofrece ningún modelo de estratificación por grupos de población (KurTz, 1987, 274-277).

En otros cementerios los análisis son más parciales, pero su resultado presenta ciertas variaciones con lo visto en La Osera y, sobre todo, en Las Cogotas. Por ejemplo, en relación a las necrópolis del oppidum de Villasviejas del Tamuja (Botija, Cáceres), si bien en la primera -El Mercadillo- apenas si se percibe una diferenciación social por ajuares, pues aunque la mayoría de las tumbas (más del 75\%) tienen algún elemento, ninguno es de gran prestigio ${ }^{12}$, en la necrópolis más tardía de El Romazal (I), la diferenciación social es más acentuada, habida cuenta que aquí el porcentaje es inverso (un $66 \%$ de las sepulturas no tiene ajuar, un $20 \%$

${ }^{12}$ Eso si, tal vez las estructuras tumulares de El Mercadillo podrian reflejar en sí una jerarquización simbólica (HERXÁNDEZ/RODrigtez, 1990; HerNÁNdez/Galix, 1996, 84), como ocurre también en La Osera. En esta necrópolis cacereña sólo se contabilizan dos sepulturas (números 6 y 11) con armas, en concreto una punta de lanza y un regatón (HER NANDEZ/GALAi, 1996.88). 
poseen elementos de adorno, y un $14 \%$ presentan armas), lo que significa admitir que el primer peldaño social viene representado por un grupo guerrero (HERNÁNDEz, 1991, 266; HernÁNDEZ, 1993, 264). Esta primera categoría social es más extensa en porcentaje en esta necrópolis cacereña que en Las Cogotas, donde las tumbas con armas tienen una proporción muchísimo más baja, en torno al 2,5\% sobre el total de tumbas (CABRÉ, 1932, 17), aunque son más en número y más lujosas sobre el total exhumadas. En La Osera el armamento está presente en el $9 \%$ de sepulturas de todo el conjunto, y por sectores en un $12,5 \%$ para la zona VI (CABRÉ et alii 1950,68 ) y en un $25 \%$ para la zona I (BAQUEDANO/MarTín, 1995, 32). Un porcentaje no muy dispar al de Botija se repite, como ya vimos, en el sector El Arenal de la necrópolis de El Raso donde las tumbas con armas suponen casi el $19 \%$ (ver nota 8); también en la necrópolis de La Coraja (Aldeacentenera, Cáceres), donde contrastan unos pocos ajuares considerablemente ricos sobre la mayoría más pobres (Esteban, 1993, 71-82), y se empieza a vislumbrar en otras necrópolis muy parcialmente conocidas, como las de la Vera cacereña, donde, a pesar de la escasez de datos, se constata una jerarquía de rangos en las tumbas, a través de elementos como los arreos de caballo y, sobre todo, las joyas de tradición orientalizante (GonzÁlfz Cordero et alii, 1990, 147; GonzÁlfz Cordero et alii, 1993; Celestino et alii, e.p.).

\begin{tabular}{|c|c|c|c|c|c|}
\hline \multirow[t]{2}{*}{ NECRÓPOÙIS } & \multirow[t]{2}{*}{ Sepulturas } & \multicolumn{2}{|c|}{ Sepulturas con ajuar } & \multicolumn{2}{|c|}{ Sepulturas con armas } \\
\hline & & c. absolutas & $\begin{array}{l}\text { c. relativas } \\
\text { (sobre el total) }\end{array}$ & c. absolutas & $\begin{array}{l}\text { c. relativas } \\
\text { (sobre el total) }\end{array}$ \\
\hline El Raso (El Arenal A-C) & 64 & 52 & $81 \%$ & 12 & $19 \%$ \\
\hline El Raso (Las Guijas B) & $\begin{array}{l}34 \\
\text { (el nủmero total es 53, pero sólo } \\
\text { 34 son susceptibles de análisis) }\end{array}$ & 31 & $92 \%$ & 5 & $15 \%$ \\
\hline Las Cogotas & $\begin{array}{l}1447 \\
\text { (el número total es de } 1613 \text { pero } \\
\text { sólo } 1447 \text { son susceptibles de } \\
\text { análisis) }\end{array}$ & 224 & $15 \%$ & 41 & $2,8 \%$ \\
\hline La Osera (zona VI) & 517 & 250 & $48 \%$ & 65 & $12,5 \%$ \\
\hline El Mercadillo & 46 & 36 & $78 \%$ & 2 & $4 \%$ \\
\hline El Romazal I & $\begin{array}{c}183 \\
\text { (el número de enterramientos } \\
\text { excavados alcanza hoy 272; } \\
\text { pero no han sido publicados en } \\
\text { detalle, por lo que tomamos los } \\
\text { datos sistematizados hasta 1993) }\end{array}$ & 62 & $34 \%$ & 26 & $14 \%$ \\
\hline
\end{tabular}


A nivel micro se pueden apuntar algunas características interesantes en los depósitos de El Arenal, la mayoría ya señaladas por Fernández Gómez. En primer lugar, casi todas las sepulturas con armas están protegidas con las lajas de cubrición ${ }^{13}$. Más indicativo resulta el rasgo de que las tumbas de guerrero más completas ${ }^{14}$ parecen seguir un patrón deposicional especial, diferenciando el ajuar cerámico del ajuar guerrero en la posición y en la protección. En el primer aspecto separando las armas de las piezas cerámicas en el plano horizontal y, lo que es más destacado, en el plano vertical a una altura superior (cercana a los $30 \mathrm{~cm}$.), especialmente visible en las tres ricas sepulturas del núcleo C (63, 64 y 66). En cuanto a la cubrición, también en estas tres sepulturas principalmente, el amontonamiento de lajas protege exclusivamente la urna cineraria y el conjunto cerámico, quedando las armas bien diferenciadas espacialmente (en dos casos a una distancia de $70 \mathrm{cms}$.) y sin cubierta protectora. ¿Se trata de un lance anecdótico fruto de la casualidad?... La cuestión es difícil de responder, pero no descartamos que esta manifestación pueda estar indicando un ritual deposicional en dos tiempos en el que las armas, sin saber la razón última (si bien no sea desacertado pensar en una pauta ideológica), ostentarían una significación especial traducida en una exposición distintiva. En otro orden de cosas, destaca el dato de que todos los soliferrea (cinco en total) aparecen intencionadamente plegados. Fernández Gómez, a diferencia de otros autores que sugieren una explicación de tipo ritual (QueSADA, 1993), apunta que para El Raso el doblamiento de estas armas arrojadizas es tan solo una medida práctica de adaptación al espacio (FERNÁNDEZ Gómez, 1986, 774-775, nota n² 454). La constatación de esta costumbre de inutilizar armas (puñales sobre todo, además de soliferrea) en otras necrópolis meseteñas e ibéricas nos lleva también a pensar, ahora para El Raso, en un rito que adquiere sentido dentro de una mentalidad guerrera. Por otra parte es indicativo el hecho de que las pinzas, sean de bronce o de hierro, aparecen casi siempre asociadas a las tumbas de guerrero. Sin embargo sorprende la ausencia en las sepulturas de El Raso de materiales como las espadas de antenas atrofiadas tipo Alcácer do Sal, los puñales y umbos del tipo Miraveche-Monte Bernorio, los arreos de caballo (sólo un fragmento, sin contexto, guardado en el Museo Parroquial) o la cerámica típicamente ibérica ${ }^{15}$ (FERNÁNDEz Gómez, 1986, 776), elementos presentes en otras necrópolis meseteñas. Estos vacíos tal vez no respondan más que a la falta de conocimiento arqueológico de un espacio cementerial tan lato como es el de El Raso.

Hasta aquí los trazos que se han podido vislumbrar sobre jerarquización social no van más allá de criterios deducidos directamente de la observación del ajuar, de la contabilización de piezas representativas y del contraste ocasional de ciertos tipos. A pesar de ser ésta la tendencia generalizada en la historiografía, la aproximación es indudablemente parcial e incom-

${ }^{13}$ Las excepciones son las número 13, 52 y 59 (y el caso dudoso de la sepultura 34).

1. Todas con lajas. excepto la sepultura 13. Curiosamente, este enterramiento de guerrero no tiene restos humanos ni urna cineraria. Tan solo se halla el conjunto de armas (espada de frontón, vaina, escudo y dos puntas de lanzil), piezas menores de hierro y una jarrita cerámica de ofrenda. No es el único caso de tumba intacta sin cenizals que encontramos en la meseta, de igual forma están presentes en el área ibérica. La opinión habitual las considera enterramientos simbólicos o cenotafios de guerreros o mercenarios muertos lejos de su terruño.

${ }^{15}$ Las mismas ausencias se siguen dando en la zona B de Las Guijas. Sin embargo, una interesante novedad introducida aqui e inexistente en El Arenal son las urnas de bronce roblonadas (seis en total: sepulturas 69, 70, 78, 80.89 y 99$)$. 
pleta. Los nuevos modelos matemático-estadísticos, apoyados en las ventajas de la aplicación informática, parecen introducir una perspectiva más neutra (también más compleja en cuanto a técnicas de análisis y programación) en el propósito de conseguir una lectura adecuada y plena sobre la jerarquización social.

\section{APLICACIÓN METODOLÓGICA: ESTIMACIÓN DE RIQUEZA Y JERARQUÍA}

Son variados los modelos de cuantificación de la riqueza de una necrópolis a partir de la asignación de valores a los elementos del ajuar, el contexto, el tamaño, la distribución y la estructura de los enterramientos, entre otras expresiones. No es ésta la ocasión para entrar en la caracterización de estos modelos. En nuestro estudio particular adaptamos el modelo de valoración de riqueza creado por Quesada para las necrópolis de ámbito ibérico (QUESADA, 1989a, I, 125-186; 1989b; 1994, 450). Muy sintéticamente señalaremos que este autor contempla dos unidades de análisis: a) el recuento simple del número de objetos en cada ajuar, y b) la elaboración de un sistema ponderado más complejo que asigna a cada tipo de objeto presente como ajuar en la sepultura una puntuación o unidad de valor determinada (wealth unit), de forma que la suma de las unidades de valor asignadas de modo constante a cada pieza determina la riqueza total del ajuar. Algunos de los factores tenidos en cuenta para la definición de la unidad de riqueza son los siguientes: el que se trate de un producto alóctono o autóctono, la cantidad de materia prima empleada y el valor intrínseco de la misma, la frecuencia de cada tipo de objeto, la dificultad técnica de elaboración, el tamaño, el tipo de decoración, etc.

La aplicación metodológica de crear unidades de valor, a partir de la riqueza del ajuar, para elevar una interpretación del ordenamiento social del grupo enterrado no garantiza resultados infalibles. Tal y como reconocen de entrada los autores introductores de estos análisis, su mecanismo es susceptible de dudas y problemas, entre los que se destacan: la restricción de los modelos interpretativos, la subjetividad en la determinación de los criterios de riqueza y de las categorías socio-profesionales de los enterrados ("tumbas de guerreros", "tumbas de artesanos", "tumbas de agricultores"...; ¿un artesano no pudo ser también guerrero?, ¿hasta qué punto nos es lícito hablar de estamentos cerrados y no de actividades mixtas?), el valor de una generalización tan amplia, la escasez de datos, el desconocimiento último de quienes se enterraban en las necrópolis conocidas (¿todos?; seguramente un sesgo de la población, pero ¿quiénes y por qué?), la duración temporal de una necrópolis, la variabilidad en el uso de la misma durante su tiempo de funcionamiento, el peso del elemento ideológico en el ámbito funerario y su identificación -0 no- con una realidad social, etc. En definitiva, ¿es el ritual funerario un reflejo real de los aspectos sociales de la comunidad enterrada o un disfraz distorsionador de los mismos? ${ }^{16}$. La tendencia actual al respecto es, partiendo del reconocimiento de que riqueza de ajuar y estatus social son dos factores emparentados pero no siempre equivalentes, construir modelos interpretativos de lo social de aproximación

${ }^{16}$ Para estas cuestiones acerca de la relación ajuar-riqueza y sociedad-sistema de enterramiento, véase RL1z ZAPATERO/ChAPA, 1990, 364-369. Un compendio de las críticas a este tipo de procedimiento de análisis se encuentra en QUESADA. 1994, 451-453. 
hipotética, siempre matizables. Un reciente ejemplo en esta línea es el trabajo de Quesada (1994), quien adapta las conclusiones del análisis que lleva a cabo (en las necrópolis ibéricas de El Cigarralejo, Cabecico del Tesoro y Baza) a las limitaciones de método antes señaladas: "La tendencia general es estudiar la riqueza de las sepulturas y las características de las mismas (tipo de ajuares, interpretación iconográfica...) como medio de obtener una aproximación sobre los estatus relativos de los distintos individuos enterrados, bien entendiendo que no es lo mismo estatus que riqueza, y que el estudio cuantificable de la segunda no nos proporciona sino una aproximación al mucho más intangible concepto de estatus o al liderazgo político efectivo" (QUESADA, 1994, 448). En la asunción de esta declaración de principios, cabe situar el trabajo que aquí presentamos.

Conviene tener presente que el modelo que aplicamos está originalmente pensado para las necrópolis ibéricas. Esto provoca que algunas valoraciones hayan sido modificadas atendiendo a la realidad arqueológica meseteña, como seguidamente indicaremos. Así, procedemos a desglosar en un cuadro la caracterización de los ajuares, contabilizando y valorando los objetos, de todas las sepulturas estudiadas ${ }^{17}$ (tabla II). Resultan un total de 26 variantes u objetos diferentes de ajuar, convenientemente valorados siguiendo las pautas anteriores $^{18}$. Sumando los puntos de cada uno de los dos criterios, número de objetos (A) y unidad de riqueza (B), obtenemos una doble estimación de la distribución de riqueza en las sepulturas $^{19}$ (tabla III).

\section{RESULTADO Y CONCLUSIONES PROVISIONALES}

Un simple vistazo a la gráfica de riqueza según el número de objetos (figura 7) revela ya ciertas pautas de comportamiento social, al menos en relación a la capacidad de acumulación de objetos, la cual no deja de ser, a pesar de las objeciones apuntadas, un valor relativo de riqueza. En el eje de abcisas se representa el número de objetos y en el eje de ordena-

${ }^{1-}$ En el cálculo se han tenido en cuenta las sepulturas alteradas (diez en total, todas del núcleo A: 10, 15, 17, 18. $25,32,34,41,55$ y 61: además de otra dudosa, la número 57) (tabla 1). Aunque parcialmente robadas, ninguna de ellas estaba totalmente destrozada, de ahí que se hayan contabilizado aceptando el riesgo de distorsión que pueda conllevar el desconocimiento de su realidad en el momento de la deposición.

${ }^{18}$ Cambios con respecto a los valores medios de las necrópolis ibéricas. La falcata, ponderada con 3.75 en las necrópolis meridionales y levantinas donde es mucho más abundante, es valorada aquí con 7 puntos. De forma inversa, el puñal ve reducida su valoración de los 7 puntos que recibe en ámbito ibérico, a la cifra de 3.75 , mucho más lógica para la meseta. El valor de la cerámica ibérica basta (1.25 puntos), que está ausente en El Raso, se ha adaptado para la cerámica indigena a mano, mientras que el de la cerámica ibérica fina (1.5), igualmente inexistente. es otorgado a la cerámica indigena a torno. Por otra parte hemos calculado otras valoraciones unitarias para objetos no contemplados en el listado de Quesada, como el botón de bronce (sepultura 52), 2 puntos, el collar de cuentas de bronce (sepultura 22), 3 puntos, el collar de cuentas de pasta vítrea (sepulturas 9, 12, 22 y 43), 5 puntos, y la navaja de hierro (sepultura 30), 2.5 puntos. (Tabla II).

19. A efectos de representación, los ajuares han sido estudiados conjuntamente en un solo bloque, sin distinción de enterramientos por núcleos (A, B y C), ni por sub-fases cronológicas. Por lo tanto el análisis se generaliza, reconociendo la imprecisión que ello pueda conllevar, al tiempo de ocupación de las 64 sepulturas del sector de El Arenal: poco más de un siglo, aproximadamente desde finales del s.V a.C., prácticamente todo el s.IV a.C., llegando hasta los primeros anos del s.III a.C. (Fernández Gómez, 1986, 871-877). Una tarea interesante como es la revisión cronológica de los materiales y el parangón con los nuevos hallazgos de Las Guijas B, con piezas tan atractivas como las procedentes de la sepultura orientalizante número 78 (FERNÁxDEz Gómez, 1996), excede los propósitos de este estudio preliminar. 


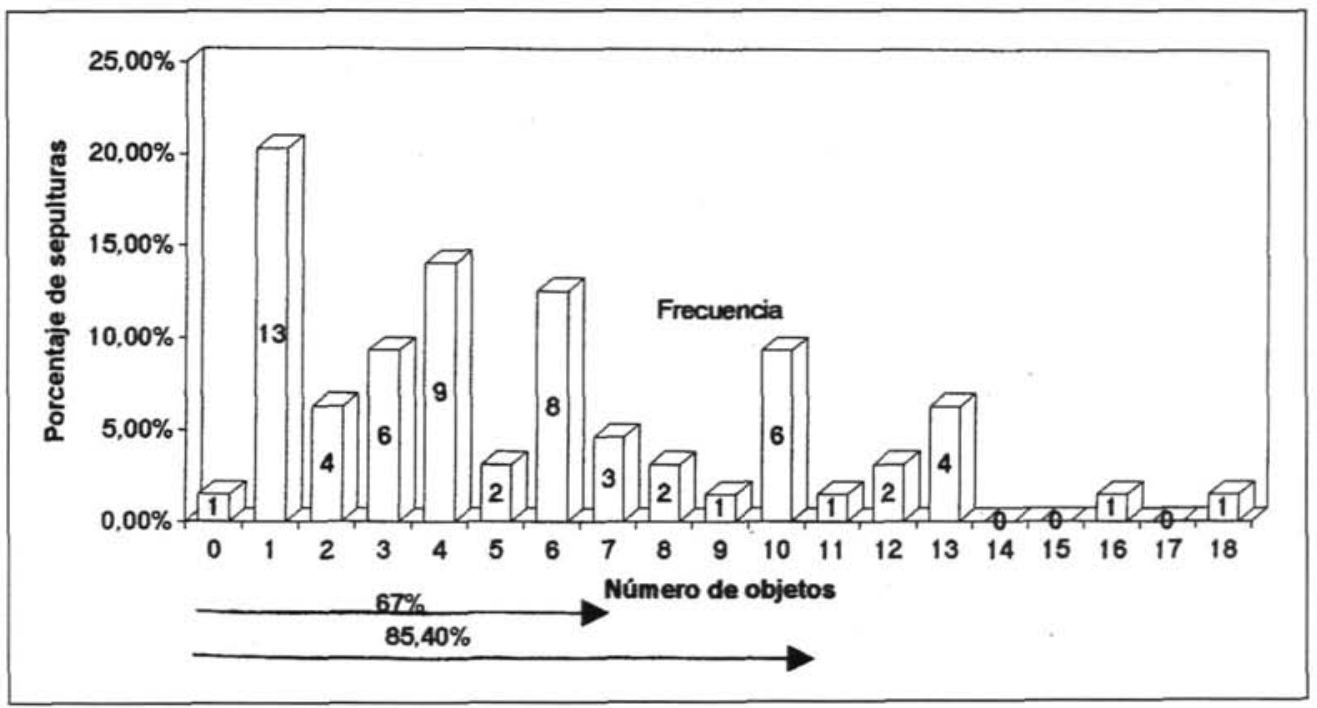

Figura 7. Distribución de tumbas según su riqueza. Criterio A: Número de Objetos

das el porcentaje de sepulturas. La cantidad de elementos de ajuar es en general bastante baja (el valor medio de objetos por tumba es de 5,6) (tabla III). El número más abundante de piezas por tumba es el de un único objeto, presente en 13 sepulturas (el 20\% del total), seguido por cuatro (en 9 sepulturas, en torno al 15\%) y seis objetos (en 8 sepulturas, próximo al 13\% del total). Más revelador son los datos que apuntan que casi el $70 \%$ de los enterramientos tiene seis o menos objetos, que el $85 \%$ de las sepulturas está por debajo de los diez, y que el $96 \%$ no tiene más de trece objetos. Dicho de otra forma, sólo ocho sepulturas (poco menos del $15 \%$ ) superan los diez objetos, y tan solo dos $(3,1 \%)$ tienen más de trece objetos (las números 42 y 20 , con 18 y 16 piezas totales respectivamente). En conjunto se trata de una curva gradual bastante irregular, con varias inflexiones en su desarrollo, que desciende desde el grupo mayoritario de enterramientos con menos de diez objetos hasta un segmento reducidísimo de tumbas con el más alto número de objetos.

La distribución de sepulturas según el criterio de unidades de riqueza ofrece un resultado más claro (figura 8). Ahora el eje de abcisas refleja las unidades de riqueza agrupadas en intervalos de dos en dos, y el de ordenadas de nuevo el porcentaje de sepulturas. La curva es más regular que la de la anterior gráfica. El mayor número de tumbas ( 15 en números reales, $24 \%$ en porcentaje) desarrollan la unidad de riqueza mínima (entre 0 y 2). La proporción de número de sepulturas decrece a medida que aumenta el valor de las unidades de riqueza, aunque no con total uniformidad. La pobreza, en este sentido, vuelve a ser predominante: prácticamente el $70 \%$ de sepulturas está por debajo del valor 8 , y casi el $90 \%$ no supera el valor 20. Son siete los enterramientos (poco más del 10\%) con un ajuar valorado en más de 


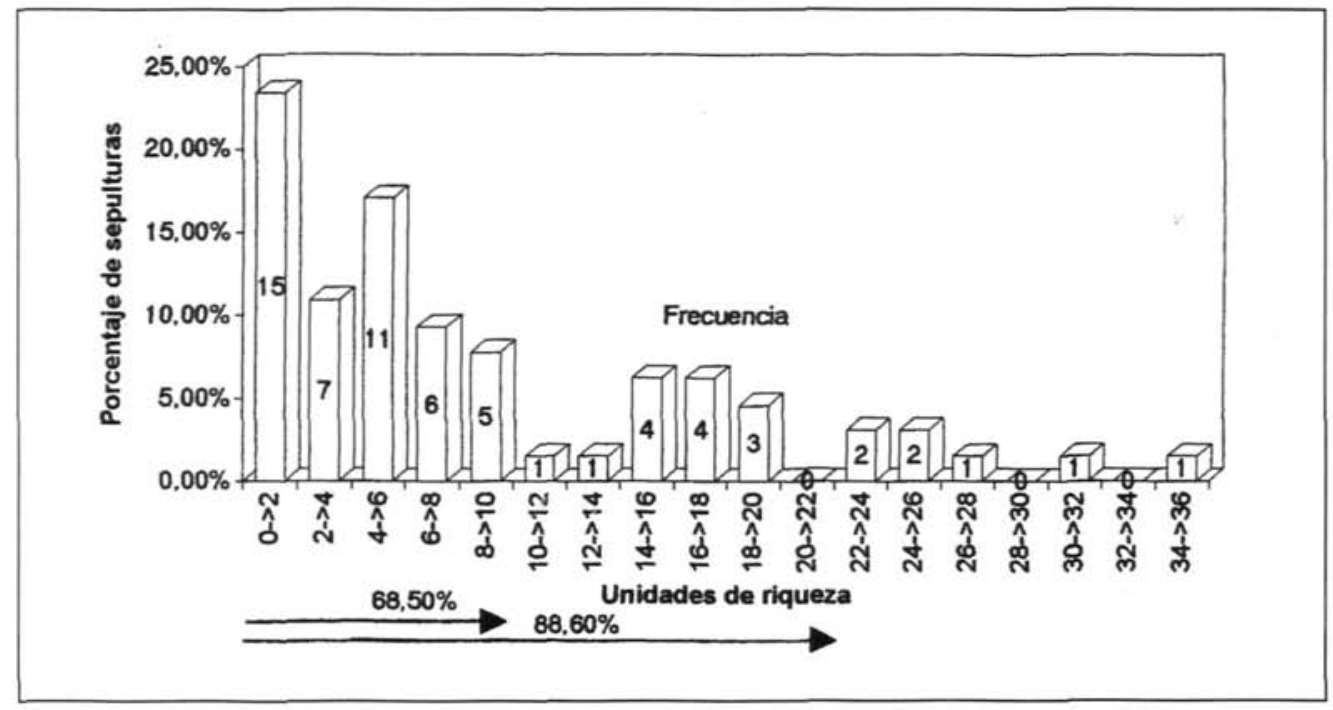

Figura 8. Distribución de sepulturas según su riqueza. Criterio B: Unidades de riqueza.

22 puntos, y sólo dos los que superan el listón de 30 puntos (sepulturas 64 y 30, ambas de guerrero, con una valorización de 35.25 y 31.25 respectivamente). El valor medio de la unidad de riqueza es relativamente bajo al estar fijado en 9.1 puntos (tabla III). Desde un punto de vista comparativo, las sepulturas más valoradas en el criterio A (números 42, 20, 4, 22, 30 y 64) están en líneas generales también a la cabeza en el índice de mayor riqueza según el criterio B (números 64, 30, 20, 42 y 22); además el reflejo de ambas curvas, dentro de un amplio margen y con algunas salvedades, es más o menos concordante.

Si solapamos el criterio de unidad de riqueza con la proporción de sepulturas con armas (figura 9) es fácil observar que éstas están en directa relación con los más altos valores de riqueza. Nueve de las once tumbas de guerrero tienen más de quince puntos, un valor relativo alto para el total de enterramientos de El Arenal. En otras palabras, diez de las doce primeras sepulturas en riqueza de ajuar presentan armas. Es indudable que el armamento se configura como claro elemento de riqueza y muy posiblemente como factor de diferenciación social.

Menos indicativa es la proporción de sepulturas con cobertura en relación al total y ordenadas de menor a mayor riqueza del ajuar siguiendo el criterio B (figura 10). Habida cuenta del porcentaje similar entre enterramientos con y sin lajas de protección (figura 3), la presencia de coberturas pétreas se extiende en todos los niveles de riqueza. Cierto es que once de las quince primeras sepulturas en riqueza la poseen, y en un segmento menor también la tienen las cuatro tumbas más ricas tanto en número de objetos como en unidad de riqueza (tablas 1 y 111 ). Pero también están presentes las coberturas en algunas de las tumbas más pobres, aunque no en tan alta proporción (figura 10). 
Tabla 2.

EL ARENAL (EL RASO, CANDELEDA). CARACTERIZACIÓN DE LOS AJUARES

\begin{tabular}{|c|c|c|c|c|c|c|c|c|c|c|c|c|c|c|c|c|c|c|c|c|c|c|c|c|c|c|c|}
\hline SE & $\mathbf{N}$ & 1 & 2 & 3 & 4 & 5 & 6 & 7 & 8 & 9 & 10 & 11 & 12 & 13 & 14 & 15 & 16 & 17 & 18 & 19 & 20 & 21 & 22 & 23 & 24 & 25 & 26 \\
\hline & & $\begin{array}{l}\mathbf{A} \\
\mathbf{B}\end{array}$ & A & A & A & A & A & ${ }_{\mathbf{B}}^{\mathbf{A}}$ & $\mathbf{A}_{\mathbf{B}}$ & A & A & A & $\begin{array}{l}\mathbf{A} \\
\mathbf{B}\end{array}$ & $\mathbf{A}_{\mathbf{B}}$ & A & $\mathbf{A}$ & A & A & A & A & A & A & A & A & A & A & A \\
\hline 4 & A & $\begin{array}{c}8 \\
1.25 \\
\end{array}$ & ${ }_{1.50}^{2}$ & & & 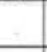 & & & & & & & & & & & & & & $\frac{1}{3}$ & & & & & & & 0.75 \\
\hline 5 & A & 1.25 & $\begin{array}{c}3 \\
1.50 \\
\end{array}$ & $\begin{array}{l}2 \\
3.50 \\
\end{array}$ & & & & & & & & & & & & & & & & $\frac{1}{3}$ & & & & & $0 \frac{1}{0.75}$ & & \\
\hline 6 & A & & $\begin{array}{c}3 \\
1.50 \\
\end{array}$ & & & & & & & & & & & & & & & & & & & & & & 0.75 & & \\
\hline 7 & A & 1.25 & $\begin{array}{c}3 \\
1.50 \\
\end{array}$ & & & & & & & & & & & & & & & & & & & & & & & & \\
\hline 8 & A & 1.25 & $\begin{array}{l}3 \\
1.50 \\
\end{array}$ & & & & & & & & & & & & & & & & & & & & & & $\begin{array}{l}1 \\
0.75 \\
\end{array}$ & & \\
\hline 9 & A & 1.25 & $\begin{array}{c}1 \\
1.50 \\
\end{array}$ & & & & $\begin{array}{r}1 \\
2.50 \\
\end{array}$ & & & & & & & & & & & & & & 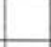 & & & $\frac{2}{3}$ & & & \\
\hline 10 & A & $\begin{array}{c}1 \\
1.25 \\
\end{array}$ & $\begin{array}{r}1 \\
1.25 \\
\end{array}$ & & & & $\begin{array}{r}1 \\
250 \\
\end{array}$ & & & & & & & & & & & & & & 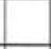 & & & & & & \\
\hline 11 & B & $\begin{array}{c}5 \\
1.25 \\
\end{array}$ & $\begin{array}{c}5 \\
1.50 \\
\end{array}$ & & & & & & & & & & & & & & & & & & & & & & 0.75 & & $\begin{array}{l}1 \\
0.75 \\
\end{array}$ \\
\hline 12 & A & 1.25 & $\begin{array}{r}5 \\
1.5 \\
\end{array}$ & & & $\begin{array}{l}1 \\
2.5 \\
\end{array}$ & & & & & & & & & & & & & & & & & & 3 & & & \\
\hline 13 & A & $\begin{array}{c}1 \\
1.25 \\
\end{array}$ & & & & & & & & & & $\begin{array}{l}1 \\
+ \\
\end{array}$ & & & & $2 \frac{2}{250}$ & & $\begin{array}{l}1 \\
4 \\
\end{array}$ & $\begin{array}{l}1 \\
3.5 \\
\end{array}$ & & & & & & & & \\
\hline 14 & B & 1.25 & & & & & & & & & & & & & & & & & & & & $\begin{array}{r}1 \\
2.5 \\
\end{array}$ & & & & & 0.15 \\
\hline 15 & A & $\begin{array}{c}1 \\
1.25 \\
\end{array}$ & $\begin{array}{c}1 \\
1.50 \\
\end{array}$ & & & & & & & & & & & & & & & & & & & & & & 0.75 & & \\
\hline 16 & A & 1.25 & $\begin{array}{c}1 \\
1,50 \\
\end{array}$ & & & & & & & & & & & & & & & & & & & & & & & & \\
\hline 17 & A & & & & & & & $\begin{array}{c}1 \\
230 \\
\end{array}$ & & & & & & & & & & & & & & & & & & & \\
\hline 18 & A & $\begin{array}{r}1 \\
25 \\
\end{array}$ & & & & & & & & & & & & & & & & & & & & & & & & & \\
\hline 19 & B & $\begin{array}{c}3 \\
1.25 \\
\end{array}$ & & & & & & & & & & & & & & & & & & & & & & & & & \\
\hline 20 & A & 1.25 & & & & & & & $\begin{array}{r}1 \\
2.25 \\
\end{array}$ & & & 1 & & & $3, \frac{1}{3}$ & $\begin{array}{c}1 \\
2.50 \\
\end{array}$ & & & & $\frac{1}{3}$ & & & & & $\begin{array}{c}1 \\
0.75 \\
\end{array}$ & $0 . \frac{2}{7}$ & 0.75 \\
\hline 21 & A & $\begin{array}{c}3 \\
1.25 \\
\end{array}$ & & & & & $\begin{array}{r}1 \\
250 \\
\end{array}$ & & $2 \frac{2}{225}$ & & & & & & & & & & & & & & & $\begin{array}{l}1 \\
5 \\
\end{array}$ & \begin{tabular}{|c|}
1 \\
0.75 \\
\end{tabular} & & \\
\hline 22 & A & $\begin{array}{c}6 \\
1.25 \\
\end{array}$ & $1_{1.50}^{2}$ & & & & $\begin{array}{r}1 \\
2.50 \\
\end{array}$ & & & $\frac{2}{3}$ & & & & & & & & & & & & & & & & & \\
\hline 23 & B & & $\begin{array}{c}1 \\
1.50 \\
\end{array}$ & & & & & & & & & & & & & & & & & & & & & & & & \\
\hline 24 & A & $\begin{array}{c}6 \\
1.25 \\
\end{array}$ & $\begin{array}{c}1 \\
1.50 \\
\end{array}$ & & & & & & & & & & & & & & & & & & & & & & & & \\
\hline 25 & A & $\begin{array}{c}1 \\
1.25 \\
\end{array}$ & & & & & & & & & & & & & & & & & & & & & & & & & \\
\hline 26 & B & 125 & $\begin{array}{c}1 \\
1.50 \\
\end{array}$ & & & & & & & & & & & & $\begin{array}{c}1 \\
3.75 \\
\end{array}$ & & & & & & & & & & & & \\
\hline 27 & A & $\frac{2}{1.25}$ & & & & & & & & & & & & & & & & & & $\frac{1}{3}$ & & & & & & & \\
\hline 28 & A & 1.25 & & & & & & & & & & & & & & & & & & & & & & & & & \\
\hline 29 & A & 1.25 & $\begin{array}{c}1 \\
1.50 \\
\end{array}$ & \begin{tabular}{|c|}
1 \\
3.50 \\
\end{tabular} & & & & & & & & & & & & & & & & & & & & & & & 0.75 \\
\hline 30 & A & 1.25 & 1.50 & & & & & 2.50 & & & & & $\begin{array}{l}1 \\
3.75 \\
\end{array}$ & & $\begin{array}{c}1 \\
3,75 \\
\end{array}$ & \begin{tabular}{|c|}
1 \\
2.50 \\
\end{tabular} & & + & & $\begin{array}{l}1 \\
3 \\
\end{array}$ & $\begin{array}{c}1 \\
250 \\
\end{array}$ & & & & & & \\
\hline 31 & B & \begin{tabular}{|l|}
6 \\
1.25 \\
\end{tabular} & & & & & & & & & & & & & & & & & & & & & & & & 0.75 & \\
\hline 32 & A & $\begin{array}{c}1 \\
1.25 \\
\end{array}$ & & & & & & & & & & & & & & & & & & & & & 1 & & $\begin{array}{l}1 \\
0.75 \\
\end{array}$ & & \\
\hline 33 & A & $\begin{array}{c}1 \\
1.25 \\
\end{array}$ & & & & & & & & & & & & & & & & & & & & & & & & & \\
\hline 34 & A & & $\begin{array}{c}1 \\
1.50 \\
\end{array}$ & & & & & & & & & & & & & $\begin{array}{c}1 \\
250 \\
\end{array}$ & & & & $\frac{1}{3}$ & & & & & & & \\
\hline 35 & A & & & & & & & & & & & & & & & & & & & & & & & & & & \\
\hline 36 & A & $\begin{array}{c}6 \\
1.25 \\
\end{array}$ & $\begin{array}{c}2 \\
1.50 \\
\end{array}$ & & & $\begin{array}{c}1 \\
250 \\
\end{array}$ & & & & & & & & & & & $\begin{array}{r}1 \\
225 \\
\end{array}$ & & & & & & & & & & \\
\hline
\end{tabular}




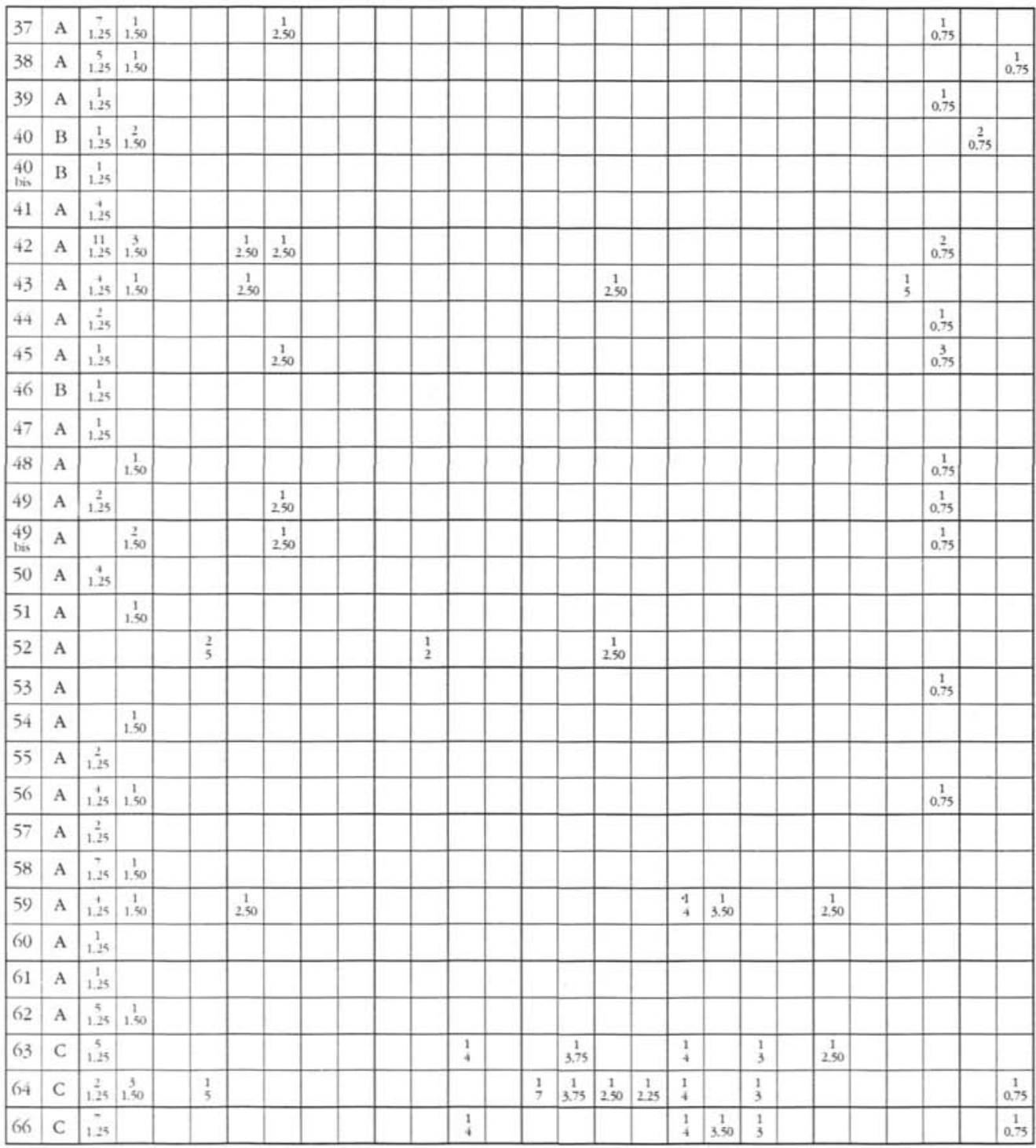

SE Número de la sepultura

N Núcleo de la sepultura

1 Cerámica indigena a mano

2 Cerámica indigena a torno

3 Cerámica importada (barniz negro precampaniense)

4 Recipiente de bronce

5 Fibula de bronce

6 Pulsera/brazalete de bronce

7 Pinza de bronce

8 Anillo de bronce
9 Collar de cuentas de bronce

10 Botón de bronce

11 Espada

12 Puñal

13 Falcata

14 Soliferreum

15 Punta de lanza

16 Regatón

17 Umbo de escudo

18 Manecilla de escudo

19 Cuchillo afalcatado
20 Navaja de hierro

21 Pinza de hierro

22 Ungüentario de vidrio policromo

23 Collar de cuentas de pasta vitrea

24 Fusayola

25 Bola de cerámica

26 Afiladora y piedras rodadas

A Criterio de NÚMERO DE PIEZAS

B Criterio de UNIDADES DE RIQUEZA (VALOR UNITARIO) 
Del resultado de la aplicación podemos anotar algunas deducciones provisionales. Los individuos enterrados en El Arenal, aunque con señales de jerarquización social, no conforman una sociedad claramente estratificada. Las curvas de riqueza (figuras 7, 8 y 9) apuntan un descenso progresivo, irregular y grosso modo continuo. No hay grandes hiatos entre agrupaciones de sepulturas de niveles de riqueza, de igual forma que tampoco se puede decir que sea una sociedad potencialmente muy enriquecida ${ }^{20}$. Es cierto que forzando una distinción se puede individualizar un bloque mayoritario de tumbas más pobres (con unidad de riqueza menor del valor 10 ; el $70 \%$ de las sepulturas), y otro minoritario que incluso podría ser seccionado en dos: grupo intermedio (riqueza entre 10 y 20 puntos; $20 \%$ de las sepulturas) y grupo reducido y con los ajuares más importantes (entre 23 y 35 puntos; $10 \%$ de las sepulturas, de las cuales sólo dos, el 3.1\%, superan la barrera de la riqueza ponderada en 30). Pero este comportamiento no creemos que se traduzca en la manifestación de nítidas clases, estratos o castas sociales (a diferencia de lo que algunos autores defienden para otras necrópolis abulenses: Martí Valls, 1985; Castro Martínez, 1986; González-Tablas, 1985). Tampoco vemos clara la identificación de grupos de enterramientos con el cumplimiento de actividades económico-políticas únicas y determinadas. Las armas predominan en las sepulturas con

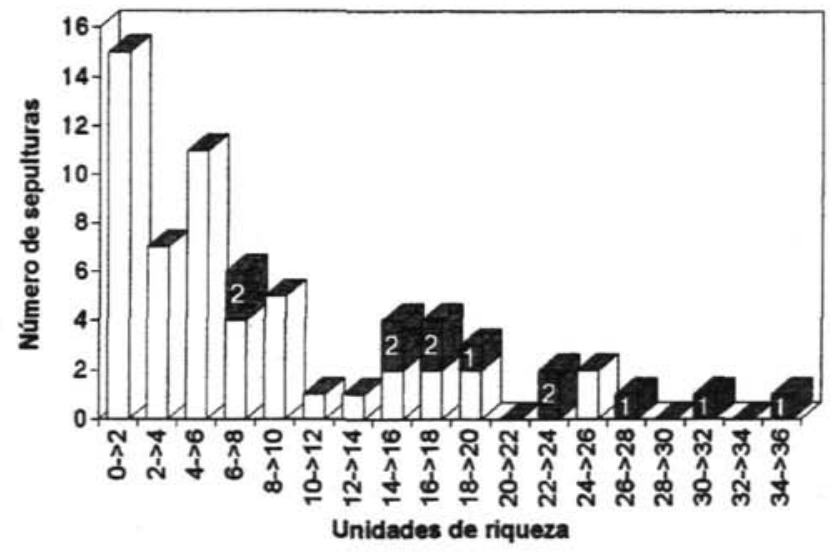

Eepulturas con armas sepulturas sin armas

Figura 9. Proporción de sepulturas con armas en relación al total y ordenadas de menor a mayor riqueza de su ajuar (Criterio B)

${ }^{20}$ Menos aun si se compara con el nivel de riqueza de algunas necrópolis ibéricas. Frente a los valores medios de 5.6 objetos por sepultura y 9.1 como unidad de riqueza en nuestra necrópolis, en El Cigarralejo (Murcia) las cifras se elevan a 12 y 21.8 , mientras que en El Cabecico del Tesoro (Verdolay, Murcia) y en Baza (Granada) las cifras están más próximas a las de El Raso. con puntuaciones medias de 4.8 y 9 y 5.1 y 11.1 respectivamente para ambos criterios (QLESADA. 1994). La aplicación de otros modelos de valorización material lleva igualmente a una estimación similar sobre la riqueza y alta jerarquización social de las necrópolis ibéricas (SAntos Velasco, 1989; Garcia CaNo, 1992; Chapa/PEREIRA, 1992; IzQlierdo/Gimevo, 1994; etc.). 
mayor riqueza, pero se registran en esa imprecisa sección media de población e incluso en dos casos dentro del grupo global de tumbas pobres con menos de 8 como unidad de riqueza. Por lo tanto, la supuesta casta guerrera no es exclusiva, aunque sí representativa, de la minoría de gentes con mayor riqueza en sus ajuares y probablemente con una posición social más elevada ${ }^{21}$.

Pero hemos de ser conscientes de que las sepulturas analizadas corresponden a un sector determinado de la necrópolis de El Raso ${ }^{22}$ y a un tiempo limitado de forma laxa al siglo IV a.C. Aparentemente en cada uno de estos sectores se reproduce en líneas generales una graduación social (la establecida por unas pocas sepulturas ricas junto a un número ascendente de enterramientos proporcionalmente más pobres), en lugar de encontrarse en un sector, pongamos por caso, exclusivamente las tumbas lujosas, en otro las intermedias y en otro solamente las más pobres. Un último comentario en relación a la organización social de estos

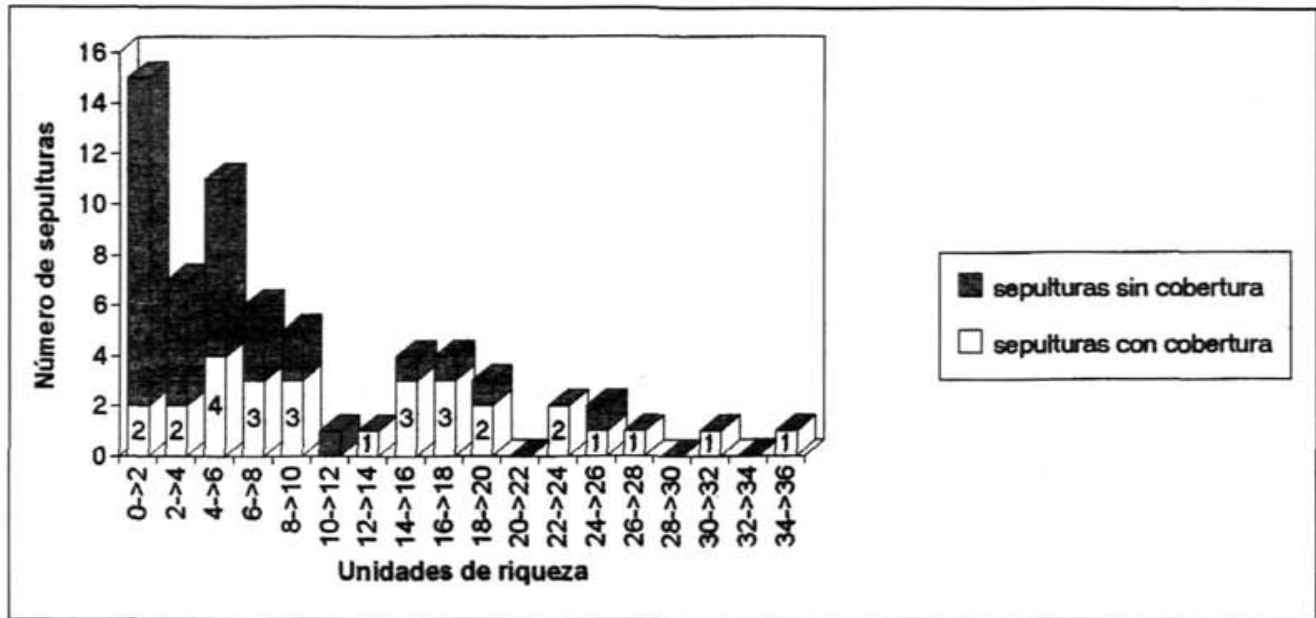

Figura 10. Proporción de sepulturas con cobertura en relación al total y ordenadas de menor a mayor riqueza de su ajuar (Criterio B)

${ }^{21}$ En la necrópolis ibérica del Cabecico del Tesoro (Verdolay, Murcia) se observa la presencia de armas (también) en tumbas pobres. Se ha propuesto que en este cementerio murciano se entierra sólo un subconjunto de la población total, el compuesto por hombres libres y tal vez propietarios, con distinto nivel de riqueza, que halla en los elementos de panoplia (en realidad en la capacidad socio-económica para costearse un equipo de armas) el signo externo a través del cual ser considerados ciudadanos (SÁxchez Mesegler/QCESADA, 1992, 373-375; QLESADA, 1994. 459. adaptado a otras necrópolis ibéricas).

${ }^{22}$ En relación a las sepulturas del nuevo sector Las Guijas B, Fernández Gómez concluye, de forma parecida a la nuestra, que no existen grandes diferencias ni una estricta jerarquización social. Según este autor "las ligeras desigualdades puestas de manifiesto en las tumbas serian tan solo un simple reflejo de las distintas funciones que cada uno desempeñaba en la comunidad. No habría plena igualdad, sino una homogeneidad general. Se trataria de una sociedad esencialmente igualitaria, con el destacamiento de ciertas minorias en relación a su función rectora" (Informe inédito). Es partidario, por tanto, de hablar de la no existencia de clases sociales. 
Tabla 3.

EL ARENAL (EL RASO, CANDELEDA). ESTIMACIÓN RIQUEZA TOTAL DE LAS SEPULTURAS (CRITERIO A + CRITERIO B)

\begin{tabular}{|c|c|c|c|}
\hline \multirow{2}{*}{$\begin{array}{l}\text { NÚMERO } \\
\text { SEPULTURA }\end{array}$} & \multirow[b]{2}{*}{ NÜCLEO } & \multicolumn{2}{|c|}{ ESTIMACIÓN RIQUEZA } \\
\hline & & $\begin{array}{c}N^{2} \text { objetos } \\
\quad(5,6)\end{array}$ & $\begin{array}{c}\text { Unidad riqueza } \\
\qquad(9,1)\end{array}$ \\
\hline 4 & A & 13 & 17.5 \\
\hline 5 & A & 10 & 19 \\
\hline 6 & $\bar{A}$ & 4 & 5.25 \\
\hline 7 & A & 6 & 8.25 \\
\hline 8 & A & 6 & 7.75 \\
\hline 9 & A & 6 & 16.5 \\
\hline 10 & A & 10 & 5 \\
\hline 11 & B & 12 & 15.25 \\
\hline 12 & A & 11 & 18,75 \\
\hline 13 & A & 6 & 17.75 \\
\hline 14 & B & 6 & 8.25 \\
\hline 15 & A & 3 & 3,5 \\
\hline 16 & A & 4 & 5,25 \\
\hline 17 & A & 1 & 2.5 \\
\hline 18 & A & 1 & 1.25 \\
\hline 19 & B & 3 & 3.75 \\
\hline 20 & A & 16 & 27.25 \\
\hline 21 & A & 6 & 10.75 \\
\hline 22 & A & 13 & 24,75 \\
\hline 23 & B & 1 & 1.5 \\
\hline 24 & A & 7 & 9 \\
\hline 25 & A & 1 & 1.25 \\
\hline 26 & B & 4 & 7.75 \\
\hline 27 & A & 3 & 5.5 \\
\hline 28 & A & 4 & 5 \\
\hline 29 & A & 10 & 14.5 \\
\hline 30 & $\mathrm{~A}$ & 13 & 31.25 \\
\hline 31 & B & 7 & 8.25 \\
\hline 32 & $\mathrm{~A}$ & 3 & 6 \\
\hline 33 & A & 1 & 1,25 \\
\hline 34 & A & 3 & 7 \\
\hline 35 & A & 0 & 0 \\
\hline
\end{tabular}

\begin{tabular}{|c|c|c|c|}
\hline \multirow{2}{*}{$\begin{array}{l}\text { NÚMERO } \\
\text { SEPULTURA }\end{array}$} & \multirow[b]{2}{*}{ NÚCIEO } & \multicolumn{2}{|c|}{ ESTIMACIÓN RIQUEZA } \\
\hline & & $\begin{array}{c}\mathrm{N}^{2} \text { objetos } \\
(5,6)\end{array}$ & $\begin{array}{c}\text { Unidad riqueza } \\
(9,1)\end{array}$ \\
\hline 36 & A & 10 & 15.25 \\
\hline 37 & $\mathrm{~A}$ & 10 & 13.5 \\
\hline 38 & A & 7 & 8.5 \\
\hline 39 & A & 2 & 2 \\
\hline 40 & B & 5 & 5.75 \\
\hline 40 bis & B & 1 & 1.25 \\
\hline 41 & A & 4 & 5 \\
\hline 42 & A & 18 & 24,75 \\
\hline 43 & A & 8 & 16.5 \\
\hline 44 & A & 3 & 3.25 \\
\hline 45 & A & 5 & 6 \\
\hline 46 & B & 1 & 1,25 \\
\hline 47 & A & 1 & 1,25 \\
\hline 48 & A & 2 & 2,25 \\
\hline 49 & A & 4 & 4.5 \\
\hline 49 bis & A & 4 & 6.25 \\
\hline 50 & A & 4 & 5 \\
\hline 51 & A & 1 & 1.5 \\
\hline 52 & A & 4 & 14.5 \\
\hline 53 & $\mathrm{~A}$ & 1 & 0.75 \\
\hline 54 & A & 1 & 1.5 \\
\hline 55 & A & 2 & 2.5 \\
\hline 56 & A & 6 & 7,25 \\
\hline 57 & A & 2 & 1.25 \\
\hline 58 & A & 8 & 2.75 \\
\hline 59 & $\mathrm{~A}$ & 9 & 19 \\
\hline 60 & A & 1 & 1.25 \\
\hline 61 & A & 1 & 1.25 \\
\hline 62 & A & 6 & 7.75 \\
\hline 63 & $\mathrm{C}$ & 10 & 23.5 \\
\hline 64 & C & 13 & 35.25 \\
\hline 66 & C & 12 & 24 \\
\hline
\end{tabular}


grupos meseteños. La peculiar configuración de los cementerios vetones en sectores diferenciados se ha identificado como una evidencia post mortem de la organización gentilicia -en clanes, gentilidades o familias de distinto grado, según las diferentes interpretaciones- de la población vetona; una de cuyas huellas más claras serían los conocidos gentilicios documentados por la epigrafía latina (Maluquer, 1954, 109; Lomas, 1980, 35; SAlinas, 1982, 68; Martin Valls, 1985, 117-118; Fernández Gómez, 1986, 929; Castro Martínez, 1986, 128-129; Blasco, 1987, 313; Sayas/López Melero, 1991, 120; Rodríguez Díaz/Enríquez Navascués, 1992, 537 y 558; REDONDO, 1993, 42, etc.). Consideramos que este principio no ha sido suficientemente sometido a un análisis interno. Nosotros también reconocemos que esta particular distribución en áreas sepulturales no es gratuita y, probablemente, responda a un ordenamiento social o familiar, cuyo sentido último se nos escapa. Pero en absoluto nos está permitido coger este dato arqueológico, trasladarlo nada más y nada menos que, por lo menos, cuatro o cinco siglos e igualarlo sin más a otro testimonio (epigráfico), tan alejado como diferente en tiempo y forma. Podremos pensar que existen agrupamientos sociales o familiares con distintos grados de riqueza en las necrópolis de Cogotas II, pero nunca que su constatación histórica venga definida por las inscripciones funerarias que incluyen los grupos familiares. En todo caso, estas últimas serían un reflejo muy tardío y alterado de tal ordenamiento social protohistórico, cuya evolución no nos es todavía bien conocida (SÁNCHEZ Moreno, 1996).

Hasta aquí llega el estudio social que nos propusimos de las gentes enterradas en El Raso, a partir del análisis del ajuar de las sepulturas del sector de El Arenal. El valor de estas páginas no va más allá de lo que una aproximación preliminar y todavía parcial puede ofrecer; por ello, relegándolo para próximos trabajos, tampoco hemos incidido en las razones que explican el diagnóstico de esta jerarquización ni en las bases económicas (ganadería, explotación minero-metalúrgica, guerra y diplomacia con agentes externos, comercio...) sobre las que el grupo minoritario más privilegiado construye los fundamentos de su riqueza material y preeminencia social. Pero si los resultados de una revisión provisional como la presente sirven de acicate para la aplicación de estudios sociales a otras necrópolis meseteñas en un futuro próximo ${ }^{23}$, nuestras expectativas quedan de sobra cumplidas.

\section{POST SCRIPTUM}

Dado el tiempo transcurrido desde la redacción (y envío) de este trabajo y el momento de su publicación, no hemos podido incluir en él un par de últimos trabajos que acaban de ver la luz, estrechamente relacionados con el contenido del mismo. Siquiera de pasada damos cuenta de su conocimiento ex posteriori a la ultimación de estas páginas. Por una parte, la publicación de la excavación de urgencia de la necrópolis de Las Guijas B de El Raso: F. Fernández Gómez. La necrópolis de la Edad del Hierro de "El Raso" (Candeleda, Ávila). "Las Guijas, B". Arqueologia en Castilla y León. Memorias 4, 1997, Zamora. Un ensayo sobre

${ }^{24}$ Lo ideal sería programar unas mismas pautas de análisis, estables y homogéneas, en las necrópolis meseteñas (sea utilizando el modelo aplicado en este trabajo u otros), para lograr resultados comparativamente más objetivos. de la forma en que se está haciendo en el mundo ibérico. Nos consta que Isabel Baquedano lleva un tiempo diseñando procedimientos de este tipo que emplea en su trabajo sobre los cementerios abulenses (un avance en BAQLEDANO/MARTIX. 1995). 
la zona I de la necrópolis de La Oscra: I. Baquedano Beltrán y C. Martín Escorza. "Distribución espacial de una necrópolis de la II Edad del Hierro: la zona I de La Oscra en Chamartín de la Sierra, Ávila, Complutum, 7, 1997, pp. 175-194. Finalmente, la brillante memoria de excavación de la necrópolis vaccca de las Ruedas: C. SANz Mínguez. Los vacceos: cultura y ritos funerarios de un pueblo prerromano del valle medio del Duero. La necrópolis de Las Ruedas, Padilla de Duero (Valladolid). Memorias. Arqueología en Castilla y León, 6,1998 , Salamanca. Si bien complementarios, los resultados de estas contribuciones no afectan directamente a las conclusiones de nuestro análisis, con atención monográfica al sector El Arenal de la necrópolis de El Raso.

\section{BIBLIOGRAFÍA}

Almagro Gorbea, M. (1994): "El urbanismo en la Hispania Céltica. Castros y oppida en el Occidente de la Península Ibérica", en Almagro Gorbea, M./Martín Bravo, A.Mª., (Eds.); Castros y oppida en Extremadura, Madrid, Complutum Extra, 4, pp. 13-75.

Baquedano Beltrán, I. y Martín Escorza, C. (1995): "La estadística y su aplicación en arqueología. El ejemplo de las necrópolis vettonas”, Revista de Arqueología, 176, pp. 26-37.

Blasco Bosqued, Mª.C. (1987): "La España Céltica: La II Edad del Hierro en la Meseta", Historia General de España y América, I-2, Madrid, pp. 297-329.

CABré Aguiló, J., (1932): "Excavaciones en Las Cogotas (Cardeñosa, Ávila). II, La Necrópolis", Memorias de la Junta Superior de Excavaciones y Antigüedades, 120, Madrid.

Cabré Aguiló, J., Cabré De Morán, M².E. y Molinero Pérez, A. (1950): El castro y la necrópolis del Hierro céltico de Chamartín de la Sierra (Ávila), Madrid.

Castro Martínez, P.V. (1986): “Organización espacial y jerarquización social en la necrópolis de Las Cogotas (Ávila)”, Arqueología Espacial. Coloquio sobre el Micro-espacio, III, Teruel, pp. 127-138.

Celestino Pérez, S. et alii, (e.p.); La influencia orientalizante en la cultura de Cogotas. El yacimiento de Pajares (Villanueva de la Vera, Cáceres), París.

Chapa Brunet, T. y Pereira Sifso, J. (1992): "La necrópolis de Castellones de Ceal (Hinojares, Jaen)", en Congreso de Arqueología Ibérica: las Necrópolis, Madrid, pp. 431-454.

Esteban Ortega, J. (1993): "El poblado y la necrópolis de La Coraja, Aldeacentenera, Cáceres", en El proceso bistórico de la Lusitania oriental en época prerromana y romana, Mérida, pp. 55-112.

Fernández Gómez, F. (1972): "Objetos de origen exótico en el Raso de Candeleda (Ávila)", Trabajos de Prehistoria, 29, pp. 273-287.

Fernández Gómez, F. (1973): "El santuario de Postoloboso, (Candeleda, Ávila)", Noticiario Arqueológico Hispano, 2, pp. 167-270.

FERNÁNDEZ GómEz, F. (1986): Excavaciones arqueológicas en El Raso de Candeleda (Ávila), I y II, Ávila. 
Fernández Gómez, F. (1991): “Un aplique de bronce de El Raso de Candeleda (Ávila)”, en La presencia de material etrusco en la Peninsula Ibérica, Barcelona, pp. 615-617.

Fernández Gómez, F. (1993): "El Raso de Candeleda (Ávila). De la prehistoria a la romanización", en El proceso bistórico de la Lusitania oriental en época prerromana y romana, Cuadernos Emeritenses, n²7, Mérida, pp. 147-190.

Fernández Gómez, F. (1995): "La Edad del Hierro", en Mariné, M., (Coor.), Historia de Ávila, I. Prebistoria e Historia Antigua, Ávila, pp. 105-269.

FERNÁNDEz Gómez, F. (1996): “Una tumba orientalizante en el Raso de Candeleda (Ávila)”, en Acquaro, E., (Ed.), Alle soglie della Classicità: il Mediterraneo tra tradizione e innovazione. Studi in onore di Sabatino Moscati. Vol.II, Archeologia e Arte, Roma-Pisa, pp. 725-740.

Fernández Gómez, F., Alonso de La Sierra Fernández, J. y López Fernández, Mª .T. (1986-87): "Evolución y cronología de El Raso (Candeleda, Ávila)”, Zephyrus, 39-40, pp. 265-271.

Fernández Gómez, F. Y lópez Fernández, Ma.T. (1990): "Secuencia cultural de El Raso de Candeleda (Ávila)", Numantia, 3, pp. 95-124.

Fernández Gómez, F., López Fernández, Mª.T. Y López Fernández, Mả.R. (1990): "A propósito de una exposición. Los pioneros de la arqueología en el Raso de Candeleda", Cuadernos Abulenses, 13, pp. 43-78.

Garcia Cano, J.M. (1992): "Las necrópolis ibéricas en Murcia”, en Congreso de Arqueología Ibérica: las Necrópolis, Madrid, pp. 313-347.

Garcia Y BeludDo, A. (1977): "Bandas y guerrillas en las luchas con Roma”, en Conflictos y estructuras sociales en la Hispania Antigua, Madrid, pp. 13-60.

García Y Bellido, A. (1986): España y los españoles hace dos mil años según la Geografía de Estrabón, Madrid, $9^{\mathrm{a}}$ edic.

González Cordero, A., Hernández lópez, M., Castillo Castmllo, J. y Torres núñez, N. (1990): "Las necrópolis de Pajares y del Cardenillo en Madrigal de la Vera y Villanueva de la Vera (Cáceres). La influencia meseteña al norte de Extremadura”, Studia Zamoriensia, 11 , pp. 129-160.

González Cordero, A., De Alvarado Gonzalo, M. y Blanco Fernández, J.L. (1993): "Las joyas orientalizantes de Villanueva de la Vera (Cáceres)", Trabajos de Prebistoria, 50, pp. 249-262.

GonZÁlez-TABlas SASTRE, F.J. (1985): "La necrópolis de Trasguija: aproximación al estudio de la estructura social de Las Cogotas", Norba, 6, pp. 43-51.

Hernández Hernández, F. (1991): "Las necrópolis del poblado de Villasviejas (Cáceres)", Extremadura Arqueológica, II, pp. 255-267.

Hernández Hernández, F. (1993): "La necrópolis de El Romazal. Plasenzuela (Cáceres)", en Mangas, J./Alvar, J. (Eds.), Homenaje a J.M $M^{g}$. Blázquez, vol. II, Madrid, pp. 257-270.

Hernández Hernández, F. y Galán Domingo, E. (1996): La necrópolis de El Mercadillo (Botija, Cáceres). Extremadura Arqueológica, VI, Badajoz. 
Hernández Hernández, F. y Rodríguez López, D. (1990): "Enterramientos de empedrado tumular de la necrópolis I de Villasviejas, Cáceres”, Verdolay, 1, pp. 71-75.

IZQuierdo Egea, P. y Gimeno Fabregat, T. (1994): “Aplicación del método de valorización contextual (Mecavon) al análisis sócioeconómico de la necrópolis de Baza (Granada)”, Homenaje al Profesor Presedo, Sevilla, pp. 513-525.

KuRTZ SCHAEFER, W.S. (1986-87): "El armamento de la necrópolis de Las Cogotas (Cardeñosa, Ávila)”, Zephyrus, 39-40, pp. 445-458.

Kurtz Schaffer, W.S. (1987): La necrópolis de Las Cogotas. Volumen I: Ajuares, Revisión de los materiales de la necrópolis de la Segunda Edad del Hierro en la cuenca del Duero (España), British Archaeological Reports, Londres.

LOMAs, F.J. (1980): “Origen y desarrollo de la cultura de los Campos de Urnas", en Historia de España Antigua, I. Protohistoria, Madrid, pp. 13-51.

Maluquer De Motes, J. (1954): "Los pueblos de la España céltica”, en Menéndez Pidal, R. (Dir.), Historia de España, I-3, Madrid (4ª Edic. 1982), pp. 1-194.

Martín VAlLS, R. (1985): "Segunda Edad del Hierro. Las culturas prerromanas", en Valdeón, J., (dir.), Historia de Castilla y León, vol. I, cap. VI, Valladolid, pp. 104-131.

Martín Valls, R. (1986-87): "La Segunda Edad del Hierro: consideraciones sobre su periodización”, Zephyrus, 39-40, pp. 59-86.

Molinero Pérez, A. (1958a): Los yacimientos de la Edad de Hierro en Ávila y sus excavaciones arqueológicas, Ávila.

Molinero Pérez, A. (1958b): "Un bronce etrusco en El Raso de Candeleda”, Archivo Español de Arqueología, 31, pp. 175-188.

Quesada SAnz, F. (1989a): Armamento, Guerra y Sociedad en la Necrópolis Ibérica de "El Cabecico del Tesoro" (Murcia, España), (B.A.R.), I y II, Oxford.

QuESADA SANZ, F. (1989b): "Informática en arqueología: un ejemplo aplicado al estudio de la jerarquización en necrópolis ibéricas", Boletín de la Asociación de Amigos de la Arqueologia, 27, pp. 36-44.

Quesada Sanz, F. (1993): "Soliferrea de la Edad del Hierro en la Península Ibérica", Trabajos de Prebistoria, 50, pp. 159-183.

QUESADA SANZ, F. (1994): "Riqueza y jerarquización social en necrópolis ibéricas: los ajuares",

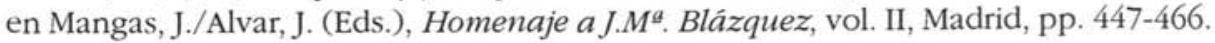

Rodríguez Díaz, A. Y Enríquez NavascuÉs, J.J. (1992): “Necrópolis protohistóricas en Extremadura", en Congreso de Arqueología Ibérica: las Necrópolis, Madrid, pp. 531562.

REDONDO RODRÍGUEZ, J.A. (1993): “Organizaciones suprafamiliares vetonas", en El proceso bistórico de la Lusitania oriental en época prerromana y romana, Mérida, pp. 37-53. 
Ruiz Zapatero, G. y Chapa BRunet, T. (1990): "La Arqueología de la Muerte: perspectivas teórico-metodológicas", Necrópolis celtibéricas. II Simposio sobre los Celtíberos, Zaragoza, pp. 357-372.

Salinas De Frías, M. (1982): La organización tribal de los Vettones. (Pueblos prerromanos de Salamanca), Salamanca, ( $2^{\mathrm{a}}$ edic., 1986).

Sánchez Meseguer, J.L. y Quesada Sanz, F. (1992): "La necrópolis ibérica del Cabecico del Tesoro (Verdolay, Murcia)", en Congreso de Arqueología ibérica. Las necrópolis, Madrid, pp. 349-396.

SÁNCHEz MORENo, E. (1995): Historia y Arqueología de los Vetones. Una aproximación crítica. Memoria de Licenciatura Inédita. Universidad Autónoma de Madrid.

Sánchez Moreno, E. (1996): “A propósito de las gentilitates: los grupos familiares del área vetona y su adecuación para la interpretación de la organización social prerromana", Veleia, 13, pp. 115-142.

Santos Velascos, J. (1989): “Análisis social de la necrópolis ibérica del Cigarralejo y otros contextos funerarios de su entorno", Archivo Español de Arqueología, 62, pp. 71-100.

Sayas Abengoechea, J.J. y López Melero, R. (1991): "Vettones”, en Solana Sainz, J.Mª., (ed.); Las entidades étnicas de la Meseta Norte de Hispania en época prerromana. (Anejos de Hispania Antigua), Valladolid, pp. 75-123. 